\title{
Design-based research as a model for systematic curriculum development: The example of a curriculum for introductory optics
}

\author{
Claudia Haagen-Schützenhöfer® \\ Department of Physics Education, Institute of Physics, University of Graz, Graz, Styria, 8010, Austria \\ Martin Hopf $\odot$ \\ Austrian Educational Competence Centre Physics, University of Vienna, Vienna, Vienna, 1090, Austria
}

(Received 4 July 2019; accepted 7 May 2020; published 4 December 2020)

\begin{abstract}
[This paper is part of the Focused Collection on Curriculum Development: Theory into Design.] Although curriculum design has a long tradition in physics education research (PER), it is often criticized for unclear or inconsistent methodologies. One reason is that the theory-into-practice aspect frequently remains blurred. Only a few curriculum projects have given insight into the rule-guided translation of learning theories into curricula and curriculum materials. This paper reports how design-based research (DBR) was used as a framework for systematic curriculum development during a six-year-long project on a middle school optics curriculum. One key feature of DBR is to deduce design principles from theoretical and empirical foundations, apply them in the creation of a curriculum, and refine them in response to data collected during successions of implementation. The design principles guide and structure the iterative cycles of design - intervention - redesign and make a systematic and nevertheless flexible design process transparent. We provide the level of detail needed to make clear how design principles were developed and applied in the creation of the optics curriculum. In addition, we use many examples to illustrate how and why the initial set of design principles was refined. We report the results of a large scale evaluation of the curriculum that shows its superiority to conventional instruction. Finally, we summarize the lessons learned during this project. This shall support other scholars in designing and implementing curricula.
\end{abstract}

DOI: 10.1103/PhysRevPhysEducRes.16.020152

\section{INTRODUCTION}

Research on teaching and learning has flourished in the last decades. Strong learning theories have been developed and validated. But there is no easy connection between those theories and the development of concrete curricula. In the past, we have collected a lot of experience in theorybased and research-led curriculum design projects for middle school topics (mechanics, electricity [1,2]). We recognized that there are many articles on curriculum design, but only a handful elaborate how learning theories shape curriculum design on an operational level (e.g., Refs. [3-5]). This paper aims to fill this gap.

The primary goal of this paper is to demonstrate how learning theories and results of previous research shaped the design of a curriculum for introductory optics at the middle school level. The starting point of our project was students' low understanding of core topics of optics as

Published by the American Physical Society under the terms of the Creative Commons Attribution 4.0 International license. Further distribution of this work must maintain attribution to the author(s) and the published article's title, journal citation, and DOI. shown in numerous studies (for an overview, see Ref. [6]). We wanted to improve this situation and so we decided to develop a theory-driven but practice-based curriculum on introductory optics for year-8 students.

Our work on curriculum development was guided by the paradigm of design-based research (DBR). A key feature of DBR is to deduce design principles from theoretical and empirical foundations, apply them in the design process, and refine them in response to data collected during successions of implementation. This idea is not new, however, only little has been published that provides the level of detail to make clear how design principles are applied in the creation of curricula [3-5,7,8]. Accordingly, it is not surprising that the DBR paradigm is often criticized for having unclear methodologies for warranting claims [8]. In this paper, we will describe how the theory-intopractice aspect guided the extensive development process of a six-year-long project on the learning of introductory optics for middle school students. Throughout this process, different research methods were used to answer various research questions at a range of grain sizes. For example, interviews were used to investigate students' understanding of white light [9] (Sec. VI A), teaching experiments were used to analyze students' learning processes (Sec. VI A), 
and large scale survey assessment studies were done to evaluate the effects of the whole curriculum [10] (Sec. VI B). In total, more than 120 interviews with students were analyzed, nearly 80 teaching experiments were conducted, and the conceptual understanding in optics of more than 3500 middle school students (Sec. VIB) was tested.

The major contribution of this paper is to focus on the generation, application, and refinement of design principles. Using the example of our optics curriculum, we outline how we deduced design principles from theoretical and empirical foundations and how they guided the creation of the initial version of our curriculum. We also illuminate how and why curriculum elements have changed over time, how and why pictorial and verbal representations have been altered, and why topics and activities are structured in a certain way in the final version.

The article is structured as follows: Sec. II introduces DBR briefly. After that in Sec. III, we introduce aspects that served as theoretical background for the generation of theory-driven and evidence-based design principles. Finally, in Sec. IV we focus on these design principles and how they guided the development of the optics curriculum. In terms of students coming to understand content knowledge, this curriculum proved to work significantly better than conventional instruction in real middle school settings (Sec. V). We provide a summary of evaluation results in Sec. VII.

\section{DESIGN-BASED RESEARCH: INTEGRATING EVIDENCE-BASED, THEORY-DRIVEN, AND PRACTICE-BASED ASPECTS INTO CURRICULUM DESIGN}

This section provides the theory-into-practice aspect behind the development process of our optics curriculum. It outlines the theoretical approach of curriculum design on a metalevel, describing how the process of curriculum design itself can be structured from a theoretical point of view.

DBR was identified as a good framework for the development of our curriculum due to its theoretical, evidence-based orientation that does not neglect needs of school practice. Design-based research can be characterized as an approach "which blends empirical educational research with the theory-driven design of learning environments"; an overall aim of DBR is to learn "how, when, and why educational innovations work in practice" [11].

Since the early 1990s, different design research movements have emerged mostly in the context of instructional design projects [12]. Different strands of design research serve different needs and have therefore different characteristics and features [13]. Design research goes back to several research programs. One of them is the movement of curriculum innovation [14]. The tradition of curriculum innovation is characterized by a sequential structure: Curricula are developed guided by already available scientific knowledge. Ready-made curricula are subsequently disseminated and implemented.

In contrast, DBR combines the educational development of instructional design and traditional education research processes.

"Design-based research is not so much an approach as it is a series of approaches, with the intent of producing new theories, artifacts, and practices that account for and potentially impact learning and teaching in naturalistic settings." [15].

DBR aims at generating new forms of content-related instruction as well as domain specific theories about teaching and learning. Both processes are seen as interdependent and are thus carried out simultaneously, in iterative cycles: Theory informs the design of the teaching and learning environments (TLEs) and is in turn modified based on empirical findings of the TLE interventions. Modified theoretical aspects then influence the instructional design of the TLEs, and so on. Later, we will present examples of such cycles.

Another characteristic feature of DBR is its claim for feasibility in "naturalistic contexts" in the sense of effectiveness and easy implementation in authentic classroom settings [15]. Consequently, practitioners are usually integrated in the design process from the beginning, as "the theory must do real work" [16].

So far, we have described DBR as practice oriented in terms of research settings, research products (ecological validity), and roles of practitioners. In addition, research questions addressed by DBR projects also demonstrate this practiceoriented aspect. While classical domain specific research seeks to identify students' conceptions and/or learning difficulties, DBR usually starts from practical problems like concrete deficits in students' performance. DBR produces instructional designs for authentic school settings. At the same time, domain specific instruction theories are generated. "A local instruction theory hence addresses the learning of a specific topic [...], offering theories about a possible learning process, together with theories about possible means of supporting that learning process [...]." [13]

The Design-Based Research Collective identifies four major benefits of implementing of DBR in education [11]:

“(a) exploring possibilities for creating novel learning and teaching environments, $(b)$ developing theories of learning and instruction that are contextually based, (c) advancing and consolidating design knowledge, and (d) increasing our capacity for educational innovation".

Points (a),(b), and (c) were our main objectives for the development of a curriculum for introductory optics at the middle school level.

Figure 1 depicts a model of the process designed to follow research and development objectives (a), (b) and (c). 


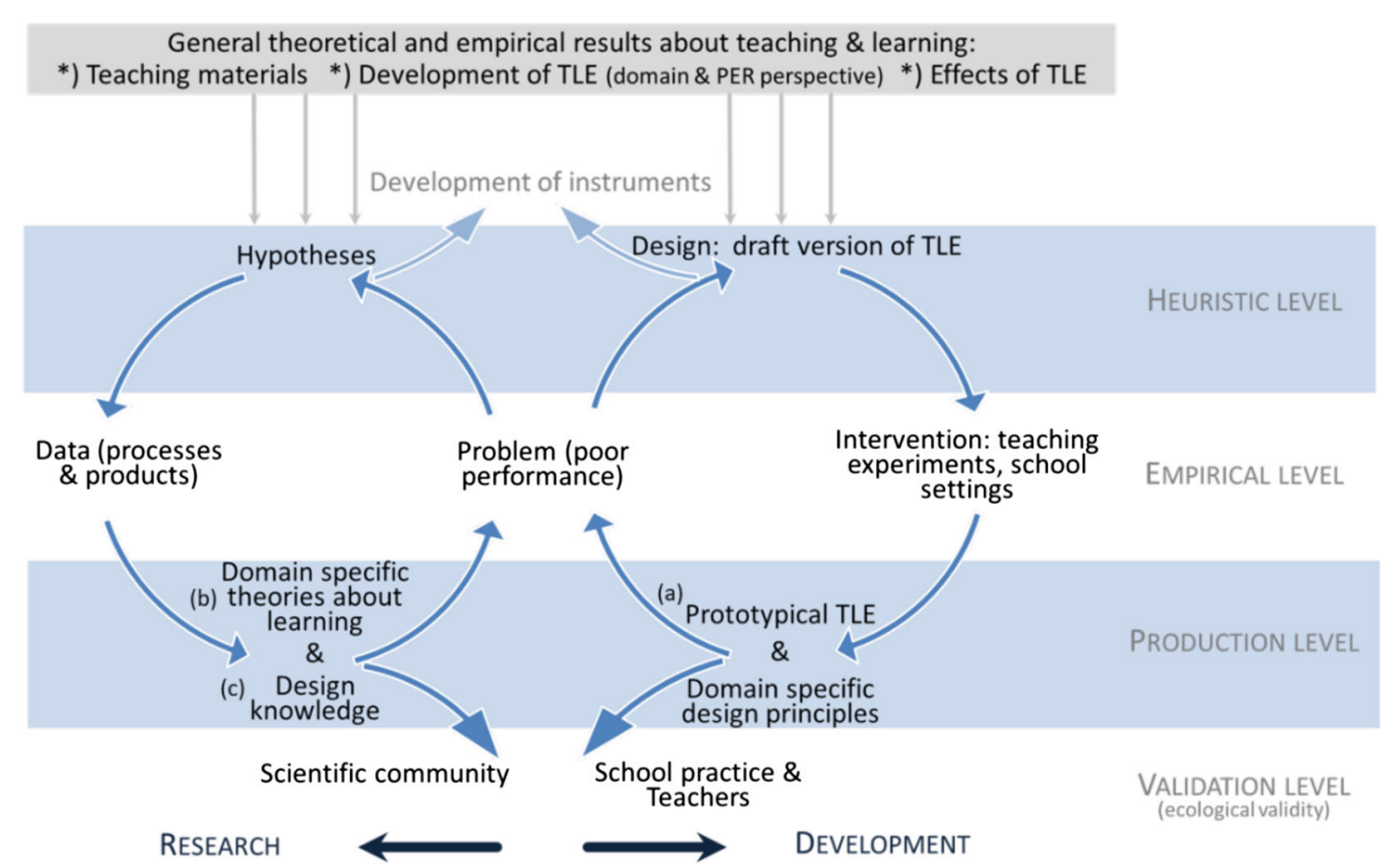

FIG. 1. Schematic model of DBR with stages in the research and development cycle. Adapted from Ref. [18]. TLE is short for teaching and learning environment. (a), (b) and (c) indicate the main objectives of our DBR project on the product level.

In general, DBR operates in two intertwined process spaces that start from a concrete, practical problem, e.g., in our case a weak conceptual understanding of introductory optics at the end of middle school [17]. This origin is located at the center of Fig. 1.

In general, the development cycle (DC) (Fig. 1, right) summarizes the rule-led development process of artifacts (teaching materials, learning strategies, curricula, etc.) for school practice. This relates to the objective of exploring the possibility for creating a novel teaching and learning environment [(a) in Fig. 1, right]. As the DC addresses the initial practical problem related to the demands of school practice, it contains a strong involvement of user feedback from teachers and school students $[18,19]$.

The research cycle (RC) (Fig. 1, left) promotes the earlier mentioned objectives of developing contextually based theories of teaching and learning [(b) in Fig. 1, left] and advancing and consolidating design knowledge in this field [respectively, (c) in Fig. 1, left]. Therefore, it mirrors the prototypical procedure of science education research. The products of this cycle are aimed at the scientific community (e.g., presentation of the findings at research conferences and in research journals).

On a structural level, both the research process and the development process are connected by four conceptual levels, which are indicated by horizontal bands in Fig. 1. Each level corresponds to a process step, which connects two successive stages of the process. Both process cycles depart from the common center, the problem stage. As the subsequent stages of the research and development cycle are different, the related process steps are operationalized differently in each process space. Table I gives an overview of the process steps and related levels of both process spaces $[18,19]$.

The first process step takes place at the heuristic level. In the DC, the approach to solve the practical problem is to develop a draft version of a teaching and learning environment that is based on research-informed design principles. In the RC, hypotheses about domain specific teaching and learning are generated based on existing research findings and theories. These hypotheses are related to the design principles of the DC, as they can be seen as hypothetical assumptions about theories concerning contextually based instruction.

The second process step is related to the empirical level. In the DC, the draft version of the TLE is tried out with students. This can be done in different formats ranging from teaching experiments to field trials in classroom settings. For the RC, the interventions provide the opportunity to collect research data.

The third process step aims at converting the results of the second step into products. In the DC, the experiences of the interventions contribute to an improvement of the draft version of the TLE. In the RC, the collected data are analyzed and local theories about contextually based instruction are generated and/or refined.

The fourth process step has two dimensions. Because of the cyclic and iterative nature of DBR, the products of the previous step may be challenged again at an empirical level and thus reenter another cycle of development and/or research. At the same time, these products need to be validated. In the DC, the created artifacts are ecologically 
validated by school practice; in the $\mathrm{RC}$, local domain specific learning theories need to be validated within the scientific community.

It is, however, important to stress the interdependency of the processes within and in-between the two process spaces. Within one process space, the single stages are interdependent. Therefore, they cannot be treated isolated or as a linear succession of steps. In addition, stages are interlinked across the two process spaces as the bands of the four conceptual levels indicate in Fig. 1. Therefore, results and findings of the corresponding stages of both cycles must be closely related to each other. As DBR is an iterative approach, the research and product cycle are usually repeated several times.

\section{CURRICULUM DESIGN: THEORETICAL AND EMPIRICAL FOUNDATIONS}

In this section, we will discuss the theory that guided the design process of our introductory optics curriculum. Or, in other words, our goal is to uncover the "theoretical ingredients" for our curriculum. As mentioned above, DBR is a theory- and evidence-driven approach to curriculum design. Teaching and learning environments are based on design principles that are deduced from theories and empirical evidence about teaching and learning in a certain domain. In the development space, these domain specific design principles function as guidelines for the design process; in the research space, they have the function of hypotheses that are tested to refine a local instruction theory about teaching and learning a certain subdomain (see Fig. 1 and Table I). Since design principles are deduced from a theoretical underpinning and from empirical evidence, this basis needs to be outlined before the specific design principles can be discussed (see Sec. IV).

At this point, it is important to stress that we will focus on the theoretical aspects that were regarded as relevant for our curriculum design. Each design process is influenced by a certain context and is therefore specified by local aspects. We, for example, worked on a certain topic (optics), framed by a certain national syllabus, for a certain group of students (year-8 students) with age related preknowledge and cognitive and verbal capacities. Consequently, in other projects, the central theories and relevant research findings [17] may differ.

\section{A. Moderate constructivism}

In general, the theoretical framework of our curriculum design is based on a moderate constructivist perspective towards learning, where learners are viewed as constructing new knowledge based on their prior knowledge and experiences. From a constructivist point of view, learning is conceptualized as building up and adapting cognitive structures as the learner interacts with the environment [20]. Therefore, learning does not only take place in formal or school related instructional situations; rather, learning happens constantly in everyday situations as well, consciously or unconsciously [21].

"In interacting with the environment, with others, and with the artifacts of technology, people form internal, mental models of themselves and of the things with which they are interacting. These models provide predictive and explanatory power for understanding the interaction." [22].

Consequently, preknowledge as well as emotional and affective experiences (attitudes, motivation, and interest) are important factors for the success of intended learning processes. We conceive learning as an individual, active, and social process, where preknowledge of the individual is activated in a social, situated way and learning environments trigger the transformation of existing cognitive structures.

\section{B. Conceptual change}

Students have already acquired numerous concepts about the natural world before they enter formal instruction. These everyday conceptions are very stable, as they have proved to be successful in everyday life. So from a learner's point of view, there is little, if any, need to change these conceptions [23]. However, these everyday conceptions are frequently at odds with scientific concepts [24].

A central goal of physics teaching is to change these everyday conceptions into more scientific ones. However, this change does not work as a mechanistic exchange from

TABLE I. Levels and process steps in the research and development cycle of design-based research. (a), (b) and (c) indicate the main objectives of our DBR project.

\begin{tabular}{lll}
\hline \hline Levels & \multicolumn{1}{c}{ Research cycle (RC) } & Development cycle (DC) \\
\hline Heuristic & from problem to hypothesis & from problem to draft version of TLE \\
Empirical & from hypothesis to data collection & from draft version of TLE to intervention \\
Production & $\begin{array}{l}\text { from data to research products (local domain specific } \\
\text { learning, design knowledge) (b), (c) }\end{array}$ & $\begin{array}{c}\text { from intervention to artifacts (prototypical TLEs (a), } \\
\text { domain specific design principles) }\end{array}$ \\
Validation & $\begin{array}{l}\text { from theories to scientific community (peer validation } \\
\text { of local domain specific learning theories, design } \\
\text { knowledge) }\end{array}$ & $\begin{array}{c}\text { from artifacts to school practice and teachers } \\
\text { (ecological validation of artifacts) }\end{array}$ \\
\hline \hline
\end{tabular}


one idea to another; rather, research has shown that conceptual change is a complex and difficult procedure [25]. Conceptual change theories, which are based on constructivism, are guides in deciding which instructional conditions and strategies are supportive for the development of ideas that are more scientifically appropriate [26].

The first education researchers to discuss conceptual change focused on the exchange aspect. More modern approaches, however, think of conceptual change as a "long-lasting gradual process" [26], where conceptions are not extinguished but restructured (in "conceptual growth" or "conceptual development"). These two theoretical frameworks coincide with two major types of instructional strategies used to bring about conceptual change: (i) discontinuous ways, resulting in instantaneous changes, and (ii) continuous ways linked to growth approaches. Although originally the discontinuous strategy of cognitive conflict was preferred, continuous approaches have gotten more attention during the last decade for several reasons. First, research findings have shown that it is quite difficult to trigger the same conflict in all students of a class at the same time, since learning is an individual process [27]. "Cognitive conflict of the kind that discrepant events provide is useful when the learner cares to engage with them and has a stake in their resolution. Otherwise, it might be commonsense to ignore them." [28]. In addition, there is empirical evidence that even if learners produce adequate answers and show a temporary mastery of concepts, misconceptions are not erased or replaced through instruction. More and more findings in neuroscience hint at a coexistence of scientific and nonscientific schemata. This indicates that concepts of different status (expert, naïve) can coexist in one person. Several studies were able to demonstrate that "when experts succeed in scientific tasks, they activate brain mechanisms usually associated with the function of inhibition" [29]. This suggests that conflicting conceptions still exist in the minds of experts and that experts-due to their expertise-are able to trigger mechanisms that inhibit the initial, but no longer prevailing, misconceptions [29-33].

These findings have several implications for the design of learning environments and curricula: First, successful learning output is tied to the prevalence of adequate conceptions over misconceptions. Therefore, instructional strategies must aim at increasing the status of intended conceptions while lowering the status of initial conceptions. Hewson [34] related this strategy to the seminal conceptual change model identified by Posner et al. in 1982 [23], writing "[t]he first condition [of conceptual change] - dissatisfaction - has the effect of lowering the status of current ideas." The remaining three of the four conditions, namely, intelligibility, plausibility, and fruitfulness, "contribute to raising the status of new ideas" [34].

Potvin [29] proposes a procedure for instruction that is supposed to produce appropriate "conceptual prevalence."
The "additive model of conceptual change" structures learning processes in three phases: (i) Introduction of programmed, intended conceptions in order to make them available for learners. (ii) Installation of inhibition mechanism: "develop and support watchfulness for contexts where intuitive prevalence produces unwanted performances". (iii) Support of prevalence: "favor durable prevalence of programmed conceptions by meaningfulness and automaticity" [29].

For the development of curricula, this has the following implications: On the one hand, domain specific key stimuli that support the activation of appropriate knowledge need to be identified and integrated in curricula. On the other hand, domain specific key stimuli that hinder learning processes need to be identified and avoided. One strategy is the installation of inhibitive "stop signs." According to Potvin [29], inhibitive stop signs are cognitive reflexes that help a learner to identify contexts where certain initial conceptions should not be used. The installation of such stop signs is thought to support the stability of appropriate concepts in learners.

\section{Educational reconstruction}

Although physics education research has established a well-grounded and detailed "catalogue of students' conceptions" emphasizing learning difficulties, instructional practices at schools are hardly informed by them. A similar situation holds true for students' interests. Research findings about students' interests on the level of context and content [35-38] are frequently ignored in learning environments. The model of educational reconstruction [39] is a way of creating instructional practices that pay tribute to constructivist ideas of learning and integrate domain specific research findings about effective learning processes (see Fig. 2). This model not only considers science subject matter but also students' perspectives on a topic. Students' perspectives include conceptions and domain specific learning difficulties as well as affective variables like interest. Following constructivist ideas about learning,

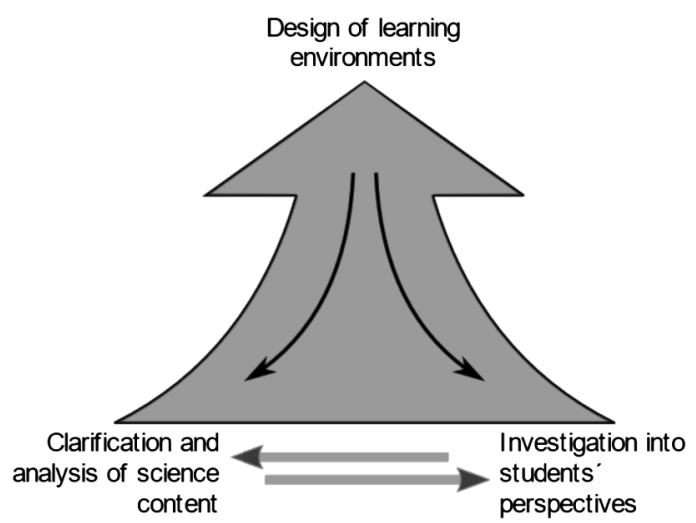

FIG. 2. The model of educational reconstruction adapted from Kattmann and Duit [39]. 
the model of educational reconstruction guides the design process of learning environments by operating in three interlinked areas: (i) "clarification and analysis of science subject matter", (ii) "student and teacher perspectives regarding the chosen subject" and (iii) "design and evaluation of learning environments" [40].

Van Dijk and Kattmann summarize the process of educational reconstruction as follows:

"Firstly, the similarities between students' conceptions and the scientific conceptions must be considered mutually. Secondly, the educational objectives and the students' ideas have to be put in a context that is understandable [and interesting] for students. The abstract scientific conceptions have to be enriched and embedded in the science content for teaching." [41].

On a more abstract level, the process of educational reconstruction can be described as a synthesis of the elementary features of topic-specific science content and of educational theories and research findings that provide guidelines for the design. The teaching and learning environment for a specific subject matter domain and setting is then created along these guidelines or design principles (see Sec. IV).

In general, educational reconstruction works on different grain sizes: On the one hand, a focus is put on the level of individual concepts, where subject matter is reconstructed according to learners' needs (which are in turn affected by preknowledge, interest, etc.). On the other hand, educational reconstruction also operates on the level of sequencing, as the sequence in which concepts are introduced and how they are interlinked influence the quality of learning processes $[42,43]$. There are several indications that traditional scientific content structures (how concepts are sequenced, etc.) are not necessarily the most effective for successful learning. In the 1960s, instructional approaches that emphasized content structure were created to help students understand how things are related, with the underlying goal being to bring students towards more expertlike conceptual understanding. However, it turned out that content structures do not necessarily support students' understanding [44].

Duit and Treagust address this issue [26]:

"The content structure for instruction needs to be designed taking into account the actual knowledge of what we know about students' pre-instructional conceptions and learning processes from conceptual change studies. Interestingly, this issue seems to be neglected or given only little attention in many studies on conceptual change. However, it seems to be essential to embed studies of conceptual change in models of instructional planning that deliberately take into account the aims of instruction and the student cognitive and affective perspectives when planning content structure for instruction".
Sikorski and Hammer stress that curriculum design does not have to adhere to disciplinary content structures to provide coherency, but that it is rather necessary that "students $[\ldots]$ are recognized as the agents of coherence seeking." [44]

This, however, implies that curriculum design processes have to focus on different levels (see Sec. IV): The microlevel is dedicated to the identification of the core ideas of a topic and how these core ideas can be reduced in complexity so that they are plausible for the target group. The mesolevel of design links different key ideas of a subtopic of the curriculum and arranges them according to the learning needs of the audience. The macrolevel functions on the biggest grain size. It reconstructs the content structure in terms of the sequencing of subtopics and their interlinking and it maps the level of consistency and coherence of recurrent concepts in all segments of the curriculum. Consequently, design principles need to focus on sequencing as well.

\section{Research on students' conceptions}

In Sec. III B, we outlined the importance of students' preknowledge in general and the influence of domain specific students' conceptions on formal learning processes. This field of students' conceptions and perspectives is one of the core fields of PER. Starting in the 1970s, numerous researchers and research projects have centered on both the investigation of students' conceptions and the identification of domain specific learning obstacles [45].

The topic of optics is one of the best-researched topics concerning students' conceptions, and a reliable catalogue of students' conceptions exists already. The scope of this paper is too limited to discuss students' conceptions on optics in detail; however, a good outline of research findings until 2009 can be found in the STCSE database (Students' and Teachers' Conceptions and Science Education) [46], and a concise overview is given in the AAAS strand maps [47]. We will, however, now provide an example that demonstrates in what way students' conceptions and related learning obstacles may guide curriculum design: The concept of vision is fundamental for the understanding of many key ideas of basic optics. If students do not grasp the idea of vision thoroughly, they have little chance in gaining conceptual insight into other subdomains of optics $[48,49]$. The main categories of student alternative conceptions related to vision were categorized by Guesne [50] and confirmed by many other researchers [51-53]. As far as the visual perception of an object is concerned, for students it seems to be very difficult to establish an adequate relationship between the light source, the object illuminated, and the observer. Even after formal instruction in optics, the majority of students either thinks that only the presence of light — conceptualized as a static entity-makes the object visible ("light bath idea"), or that light just needs to be beamed on an object for the object to be visible 
("illumination of an object"). In both conceptualizations, the link between the object that reemits light and the visual system of the observer is neglected. A smaller number of students follow the idea that there is some kind of mechanism in the eyes that, when active, enables them to perceive their surroundings visually ("active eye"). In this case, a relation between the illuminated object and the observer is established, yet in the wrong direction: the eye is not conceptualized as a receiver of light, but as a kind of sender "scanning" the object [50].

The everyday use of language is one source of alternative conceptions about vision-as it is for other key concepts of optics.

"Historically, language was developed under the influence of visual perception and well before our present understanding of vision was reached. Thus many linguistic constructions do not conform to present-day scientific knowledge. Phrases such as 'her eyes shine', 'his face radiates light', 'she casts a glance', 'light fills the room', 'the mirror reflects images' and 'the tree casts its shadow' are at odds with contemporary optics." [54].

The knowledge about such alternative ideas and their possible sources together with the idea of conceptual prevalence (see Sec. III B) provides guidance for the design of the TLE. In the case of vision, the implication is that the status of a sender-emission-receiver model (see Sec. III E) needs to be increased by the TLE, while the status of the light bath conception needs to be lowered. In addition, it seems to be necessary to avoid certain key stimuli like the use of such phrases as mentioned in the citation above. The example of students' conceptions on vision and related learning obstacles is prototypical for the relevance of research in evidence-based curriculum design.

\section{E. Teaching and learning introductory optics: conventional approaches and preliminary work}

Research literature outlines a number of basic concepts which are essential for the understanding of introductory optics: propagation of light, light and shadow, light and vision [sender-emission-receiver (SER) model], interaction of light and matter (scattering, reflection and refraction as basic processes of image formation), as well as light and color $[50,55]$. These topics are usually rooted in the middle school syllabus for physics. However, research results of PER show that students frequently have a poor understanding of these concepts even after formal instruction. This situation holds also true for Austrian year- 8 students $[17,56]$.

Unfortunately, this knowledge about domain specific learning difficulties has only reached a minority of physics teachers [57]. Research focusing on the analysis of conventional instruction and on schoolbooks identifies a number of concrete problems that contribute to student learning difficulties [56]. One issue that has been discussed is that many textbooks introduce ray diagrams, an abstract representation, too early. An additional issue is that basic ideas like the SER mechanism are not used in the explanation of more complex optics concepts like image formation, body color, etc. This is not only true for textbooks at the secondary level, but also at the university and college level (see, e.g., Refs. [58-61]).

These research findings have led to the development of several instructional strategies for different subtopics of introductory optics, which have been empirically tested to some extent (e.g., Refs. [62-66]). A particularly elaborate curriculum for introductory optics, informed by empirical findings of Jung (e.g., Refs. [67,68]) and Wiesner [53], was published by Wiesner, Herdt, and Engelhardt [69-72]. Herdt evaluated the curriculum in a comparative study with conventionally taught classes and was able to find a significantly better performance of the intervention classes. Elements of this course and findings of other research projects in introductory optics $[62,65,73]$ were incorporated into the domain specific design principles that guided the formation of our curriculum.

\section{TRANSLATING THEORETICAL ASPECTS AND RESEARCH-BASED EVIDENCE INTO DESIGN PRINCIPLES: THE EXAMPLE OF A CURRICULUM FOR INTRODUCTORY OPTICS}

The theoretical and empirical foundations presented in the previous sections serve as a basis both for the design process of our optics curriculum and for the theory generation in our research. In the paradigm of DBR, design principles guide the curriculum design process; at the same time, they take the role of hypotheses that are tested to refine local instruction theories about teaching and learning. To exemplify this theory-into-practice aspect, we will now discuss how we deduced design principles from theoretical and empirical foundations as we developed a curriculum for introductory optics for middle school students.

As mentioned earlier (see Sec. II), DBR is a cyclic process, which starts at a concrete problem from school practice (see Fig. 3, middle-left). In our case, the starting point was the poor conceptual knowledge of Austrian middle school students after their formal instruction in optics [17]. After identifying and analyzing the practical problem in stage one, we developed a draft version of the teaching and learning environment in stage two (see Fig. 3). This TLE draft was based upon design principles, which were in turn deduced from theory, preliminary developments, and research findings (see Sec. III E, Sec. III D).

In what follows, we separate our design principles into two categories, general design principles and domain specific design principles. General design principles build the overarching theoretical framework, they mirror the theoretical approach of a curriculum design project. Domain specific design principles are local. They are in 


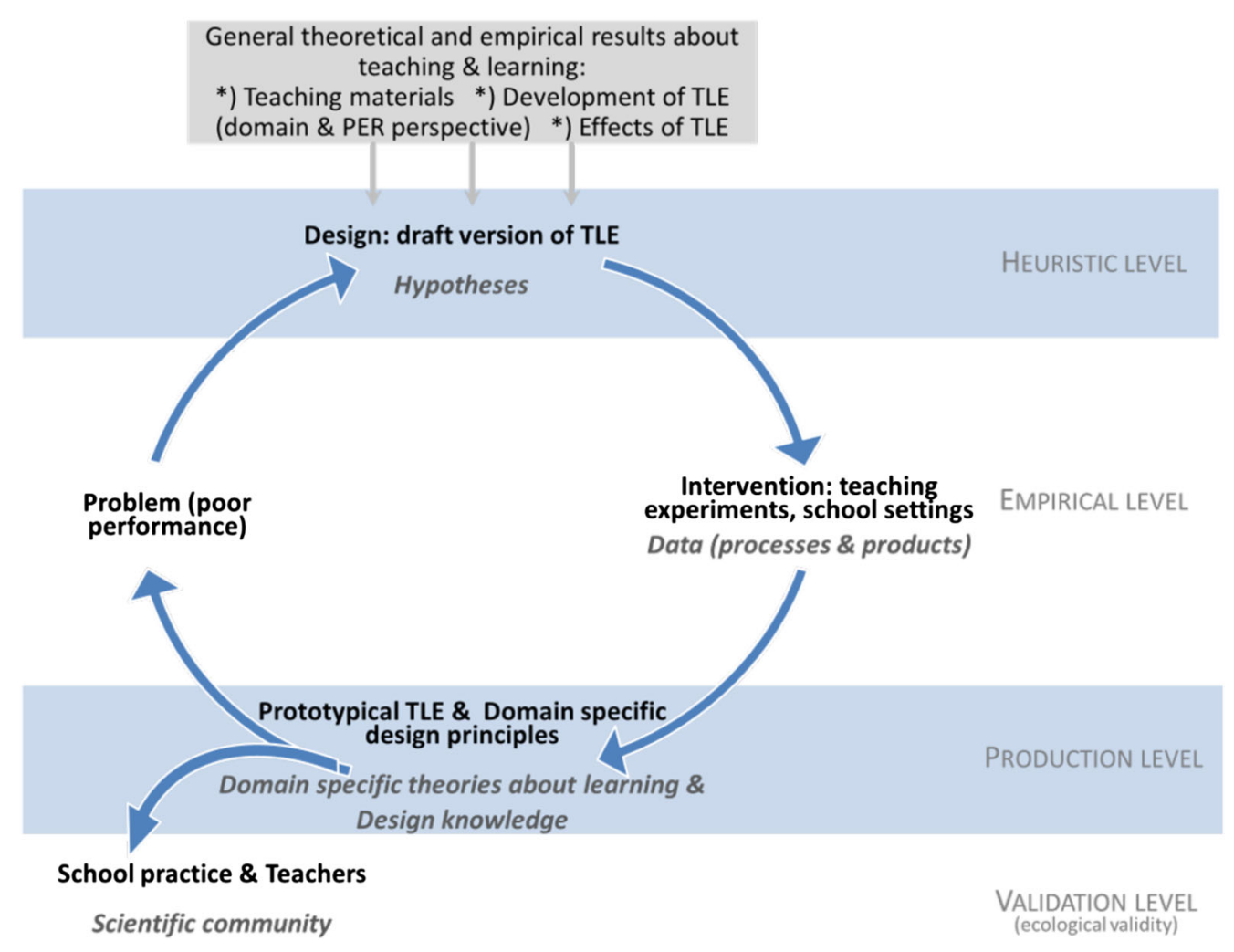

FIG. 3. Model of DBR with superposed development and research space. The successive stages of the development process are written in bold, black letters, related stages of the research process in gray italics.

general accordance with general design principles in the sense that they do not contradict them, but rather echo them on a more local level. Local refers, for example, to a certain topic or subtopic of a domain, to a certain group of learners or a certain teaching context (e.g., formal instruction, physics lessons). Domain specific design principles inform the content structure of a curriculum and they also shape curriculum elements. General design principles and domain specific design principles are not in a one-to-one relationship. A domain specific design principle can resonate with more than one general design principle at a time. The section on domain specific design principles (Sec. IV B) illustrates this with several examples.

We will first present the initial version of those principles that guided the development of the draft version of the curriculum (see Fig. 3). In the course of the iterative succession of design, intervention, and redesign, this initial set of design principles was transformed in response to collected data. The final design principles make up the local instruction theory about teaching and learning introductory optics. In a later part of this paper (Sec. VI A) we present how they have changed and for what reasons.

\section{A. General design principles}

General design principles specify theoretical aspects of teaching and learning on a general level. They also emphasize the theory-driven and evidence-based approach in our curriculum design project, in which decisions are always tied back to theories or are based on existing research findings.

\section{1. (G1) The development of the curriculum is based on findings from research on learners' perspectives and students' conceptions}

Constructivist learning theories emphasize learners' prior knowledge and experiences as the most relevant factors for successful learning processes [23,26,74], as discussed in Sec. III A. Consequently, it is necessary to build on students' ideas [5]. Research on students' conceptions is a reliable source to shed light on students' perspectives in a certain teaching context. Educational reconstruction (Sec. III C) takes this into account as each subject matter concept is contrasted to documented students' conceptions and reconstructed on this basis for the curriculum.

We mainly identified students' conceptions on optics based on literature research. In addition, we used a nationwide testing (see Sec. V) as a kind of pre-assessment to check whether in literature documented students' conceptions can be replicated in our target group of learners. In the case of ambiguities concerning students' ideas during the implementation phases, we conducted additional research on students' conceptions (see Fig. 4, cycles A, C, IV). 


\section{Iterations and Interventions}

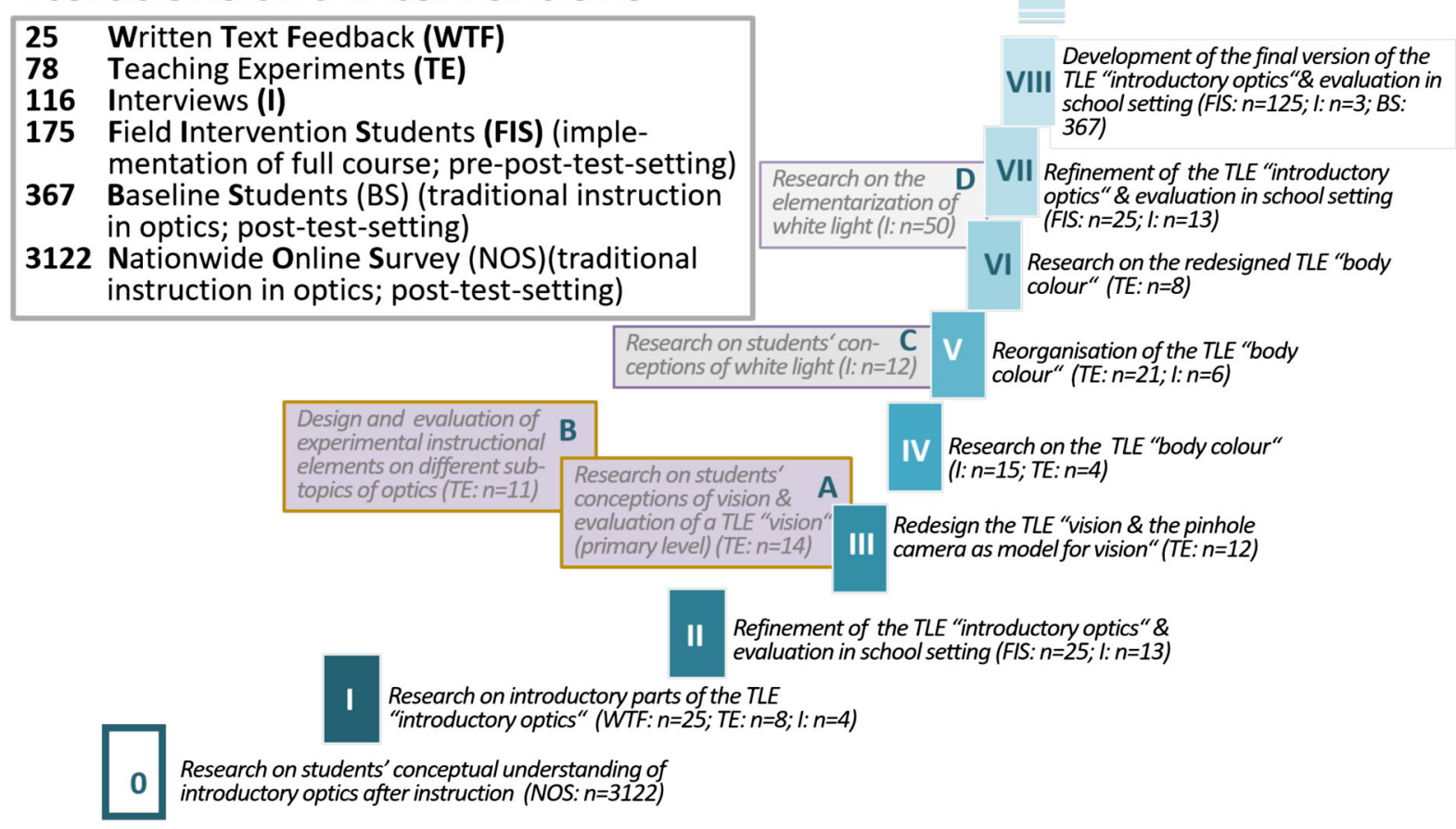

FIG. 4. Design cycles and interventions in the design process of the optics curriculum.

\section{2. (G2) Learners are active participants in teaching-learning processes}

As outlined in the section on moderate constructivism (Sec. III A), learning is seen as an active, individual process that takes place in social contexts. Learning environments have the function of scaffolding and guiding learning processes towards an intended direction [3]. Thus, the curriculum provides learning activities that induce learning processes by elements of cognitive activation.

In the optics curriculum, most topics start with a prompt that introduces the key ideas and central issues which students will work on. Later sections of the curriculum additionally use different types of activities to reactivate key ideas of earlier topics. After this initial phase of cognitive activation, a central phenomenon is usually introduced which students explore, guided by input and active learning tasks. Active learning opportunities are integrated in the curriculum either in the form of pair work or individual working phases that are typically followed by group or whole class discussions. These tasks actively engage students, structure instruction and follow a guided approach. Unguided open learning situations based on "learning by doing" or "trial and error" approaches are avoided as they may endanger students' learning success [75] by inadvertently supporting the status of initial misconceptions, instead of introducing intended conceptions and increasing their status as discussed in Sec. III B. So, we follow a student centered and active learning approach. Emphasis is put on cognitive activation.

\section{3. (G3) Conceptual change is triggered by continuous strategies rather than by cognitive conflict}

As discussed above (Sec. III B), conceptual change researchers describe various strategies to shift alternative conceptions towards more scientific ideas. Although the strategy of cognitive conflict originally predominated in research-based curriculum development, neurological findings in recent years suggest alternative approaches that follow enrichment or prevalence strategies [26,29]. Consistent with these latter findings, our design decisions aim to avoid activating initial students' conceptions that may hinder the successive learning processes. In contrast, the optics curriculum seeks to integrate key stimuli that activate desired knowledge elements and thus follows a prevalence strategy (see Sec. III B). The identification of key stimuli that hinder or support learning processes is carried out in learning process studies, which are part of the research cycle of DBR.

As we acknowledge conceptual change as a long lasting, gradual process that develops over time, we are aware that learning processes do not immediately result in targeted ideas. The continuous strategy of conceptual change takes this into account as it supports the development of fruitful sub concepts ("partial knowledge" [3]). Only when conceptual status of these sub concepts has been raised, instruction moves on to more complex concepts. In terms of the optics curriculum this means for example: only when students have acquired a solid understanding of how we see primary light sources based on a sender-receiver model, 
instruction moves on to the mechanism behind the perception of secondary light sources.

\section{4. (G4) Learning obstacles are explicated in the learning process to install inhibitory "cognitive stop signs"}

This curriculum design tries to avoid the reinforcement of existing students' conceptions. "Therefore, [students] must be made aware of the insufficencies of their misconceptions and warned that in certain identified contexts, they have limits" [29]. At the same time, inhibition mechanisms (Sec. III B) are used to train students to avoid typical error patterns. In the course of the optics curriculum, catchy mottos are introduced that function as key stimuli in the sense of inhibitory "stop signs". These mottos are used at critical parts of the curriculum, where students typically tend to fall back to their alternative conceptions. The mottos remind students of the limitations of these conceptions, inhibiting their use. For example, when students work on the sender-receiver idea for primary light sources, we implement the motto "From nothing, nothing can come" as a cognitive anchor. This is taken up at several instances later in the curriculum, for example when students are supported in developing an appropriate idea on how we see secondary light sources.

\section{5. (G5) Learning paths go from individual, subjective perceptions to abstract subject matter principles, which are then tied back to initial, individual perceptions}

Above, we discussed the influence of everyday experiences on learning processes (see Sec. III, for example). We have also reviewed the evidence for the coexistence of an everyday perspective and a more scientifically oriented view on subject concepts. A goal of our optics curriculum is for students to be aware of these two perspectives, so as to consciously switch between them and to contrast them on a metalevel. Typical instructional interventions tend to provide abstract subject matter principles based on individual perceptions of everyday life. The optics curriculum, in contrast, develops abstract subject matter principles from personal experiences; what's more, these principles are then tied back to these initial, individual perceptions. Several sections of the curriculum start with experimental observations. There, the students are asked to describe their personal perceptions. Then the physics perspective is introduced and gradually used to systematize initial perceptions (see DS5).

\section{6. (G6) Learning processes are situated in contexts that are appealing to students}

Learning physics in formal school settings is often completely decontextualized or relies on contexts that only marginally fit the interests of the majority of learners [36,76-78]. Frequently, students see little relevance in understanding physics for their everyday life. Constructivist views on learning processes stress, however, the importance of cognitive and affective components (Sec. III A) and the model of educational reconstruction (Sec. III C) incorporates both aspects. Therefore, in the optics curriculum, the development of scientific ideas is situated in contexts that are relevant for students' everyday life and have shown to be interesting. Namely, the optics curriculum utilizes social, environmental, and biological contexts, including both health issues as well as natural phenomena $[36,76,79,80]$.

\section{7. (G7) Concept development is supported by learner-friendly forms of representations}

Science education researchers have stressed the importance of external representations for learning processes for several decades. Researchers have argued that the simultaneous presence of multiple representations is critical in order to establish representational coherence [81-84]. "However, just combining words, pictures, mathematical expressions or other kinds of visualizations does not automatically guarantee meaningful learning." [85]. So, the choice of external representations needs to be well reflected in the design of learning environments, curricula, and test instruments. It is necessary to ensure that the target group is able to decode relevant key ideas of representations on the basis of their preknowledge.

Special attention should be given to multiple representations in order to establish representational coherence [82-85]. As discussed in Sec. III of this paper, students' preknowledge, experiences, and learning needs are essential for the design of successful learning processes. These prerequisites should not only be considered on the content level, but also on the level of representational aspects like in verbal or nonverbal representations of subject matter $[85,86]$. In the development process of the optics curriculum, verbal and nonverbal forms of representations are therefore reconstructed to reduce learning obstacles. In the first version of the curriculum we tried to integrate as many forms of representations as possible that have shown to support students' learning processes in previous research projects. In addition, students' understanding and acceptance is checked in teaching experiments. Where necessary, forms of representations are adopted towards students' needs, as already suggested by Linn et al. [5]. Van Zee et al. [87] show, for example, that students can also be the inventors of such modified representations.

\section{8. (G8) Learners' needs determine the content structure; the scientific subject content structure does not have priority}

In the section on educational reconstruction (Sec. III C), we discussed the importance of the sequence of content segments for learning processes. Most curriculum design projects focus on the reconstruction of the subject content from an expert's perspective, neglecting the fact that scientific content structures are not necessarily appropriate 
for learning $[26,88]$. The curriculum for introductory optics considers aspects of content structure on the mesolevel and on the macrolevel of design (Sec. III C) from the perspective of what is most sensible to the learner. We use learning process studies and interventions in authentic school settings to identify hints indicating inconsistencies in the content structure.

\section{B. Domain specific design principles}

In contrast to the general design principles, domain specific design principles refer to teaching and learning in the field of introductory optics. They are in resonance with general design principles but are more local and specific as they guide the design process on a concrete level. A domain specific design principle cannot be interpreted as the mere specification of a general design principles, but it is influenced by several general design principles. Like general design principles, domain specific design principles are also theory-driven and research-based.

The initial set of domain specific design principles for the optics curriculum was derived from findings on teaching and learning of optics (e.g., Refs. [62-64,89]). The domain specific design principles do not only guide the development process of the teaching and learning environment; they also take a similar role as hypotheses do in classical research processes: They are refined, expanded, or revised in the context of the research cycle to finally arrive at a refined version of teaching and learning theories specific to introductory optics for middle school students.

PER literature on teaching and learning introductory optics documents a large number of findings, many of which we referenced in the development of the optics curriculum. As the length of this paper is limited, the following section can only provide a condensed summary of the most important principles. However, we give examples how domain specific design principles are applied and in what way they resonate with general design principles. The selection of domain specific design principles reported here tries to give the flavor of our curriculum and underline those aspects that are frequently neglected in conventional instruction (Sec. III E).

\section{1. (DS1) The sender-emission-receiver (SER) mechanism of vision is an essential concept for the understanding of many subtopics of introductory optics. Thus, it is introduced at the beginning of the curriculum and used throughout}

As discussed in Sec. III E, it is well known that a basic understanding of how vision works is essential for a basic understanding of optics. Students' perspectives on vision have been investigated thoroughly. Research reveals a number of very stable alternative conceptions as reported in Sec. III D (illumination, light bath, active eye). General design principle G1 states that students' preknowledge is

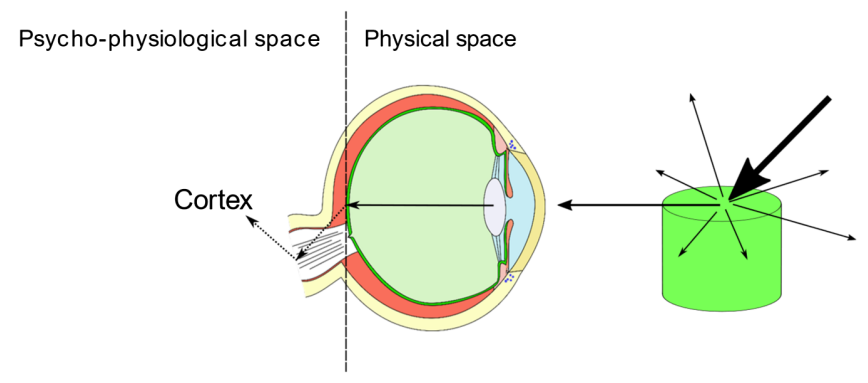

FIG. 5. Mechanism of vision from physical and psychophysiological points of view. The process of human vision is divided into two parts: the physical and the psycho-physiological part. The physical part integrates propagation of light, scattering, and image formation. The path of light runs from the light source (sender) via the perceived object to the retina (receiver). In the psycho-physiological part, the cerebral interpretation of the effects of the light on the retina takes place [51].

essential for their learning. Consequently, typical students' conceptions are among the guiding factors how instructional elements are structured in the first version of the TLE. Research results also stress the importance of the SER mechanism (see Fig. 5) for the understanding of many concepts of introductory optics (see Sec. III D). Therefore, it is introduced right at the beginning of the curriculum, when the process of vision is introduced. These assumptions about the SER mechanism are tested during successive rounds of implementation and refined and retested if necessary.

For secondary light sources, the SER mechanism is extended to a sender-emission-scattering-receiver (SESR) mechanism (see Fig. 5). The SESR model is integrated in the educational reconstruction of different subtopics of the curriculum (e.g., image formation by mirrors and lenses, body color). This procedure follows general design principle G3 as it is in harmony with a conceptual growth approach: Learning processes are supported by a step-bystep strategy (first SER then SESR). Key concepts are activated again and again throughout the curriculum.

The process of vision is reconstructed with emphasis on the physical part; the psycho-physiological part is mentioned but not explained in detail (see Fig. 5).

Via the use of representations, this concept is anchored in two different ways throughout the curriculum. First, visual representations in the curriculum (iconic representation) explicitly include the observer (receiver) [54,90] (see Fig. 6). This resonates with general design principle G7, as previous research shows that the integration of the observer helps to anchor the SER mechanism better. Again, this assumption is tested during implementation.

Second, a catchy motto is introduced ("From nothing, nothing can come") (symbolic representation) when the model is explained for the first time. This motto stresses the concept that objects are visible only when they send off light; if they do not ("from nothing") they cannot be seen ("nothing can come"). We use and connect multiple 

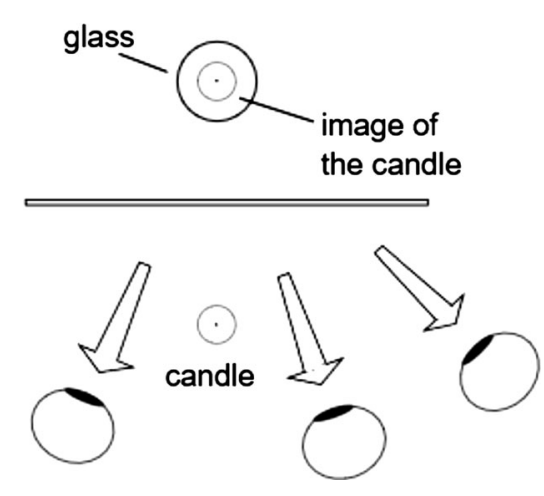

FIG. 6. Example of visual representations including the observer.

representations here to support students' deeper understanding [86]. In addition, these representations are intended to function as inhibitive stop signs that cognitively warn students if they fall back to their alternative ideas about vision (see Secs. III B and III D). This procedure is related to the theoretical underpinning of general design principle G4.

On the level of content structure, this model is introduced at the beginning of the curriculum, as it is essential for a basic understanding of many phenomena [90]. Following a prevalence strategy (see Sec. III B and general design principle G4), it is repeated again and again in different phases of this curriculum to actualize its basic idea. This strategy is informed by general design principle G8.

In terms of applied contexts, we introduce the idea of how vision works with the help of visual systems of different creatures (human beings, cephalopod). For the perception of secondary light sources, we analyze the phenomenon of orange clouds during sunset. In a later part of the curriculum we address health issues related to the quality of sunglasses based on the SESR model. This choice of contexts is based on general design principle G6.

\section{2. (DS2) Physics terms are adapted towards the learners' needs}

Above, we have emphasized the importance of appropriate and comprehensible representations (G7), ${ }^{1}$ as well as the relation between everyday language, preknowledge, and alternative conceptions (G1). Domain specific principle (DS2) incorporates both ideas, for example, by avoiding the use of the term "light source."

The term light source is a verbal representation that may induce conceptions that inhibit learning [10,55,70]. It is mostly used for primary sources and thus activates the conception that a light source emits light because it produces light (G1). This idea eventually blocks the understanding that the visual perception of an object is always based on a sender-receiver mechanism, even if the

\footnotetext{
${ }^{1}$ Resonances with general design principles are indicated by the abbreviation of the general design principle in brackets.
}

object itself does not produce light. We can perceive objects when they send off light. For our perception, it is irrelevant whether the light is sent off by primary light sources or by illuminated objects (secondary sources).

Instead of the term light source, the term sender is used for objects that emit light continuously and the term reemitting sender for objects that emit (reflect) light only after absorption. Sender in both terms denotes that light is sent off from these objects, which is the relevant condition for their visibility. In accordance with the prevalence model of conceptual change (cf. Sec. III B), the optics curriculum stresses this aspect, as it is a prerequisite for the SER mechanisms and thus for understanding the concept of visibility (G4). Many schoolbooks categorize light sources as artificial or natural. This distinction is also avoided, as it does not contribute to the understanding of the process of vision and it creates additional cognitive complexity [10,55,57].

\section{3. (DS3) A ray of light is an idealization. Thus, light rays are introduced as a model step by step}

It is a widely spread convention to represent propagating light by straight lines (light rays). Physics textbooks typically use this type of representation right from the beginning, when the optics chapter starts. In most cases, the model character of this form of representation is not discussed. Namely, students are never told that light rays are neither material objects emanating from light sources, nor are they visible per se; rather, they are just a two-dimensional representation of a three-dimensional phenomenon that indicates, "how information travels in space" [90]. However, an adequate use of this model is crucial for successful learning. In physics classes, students tend to have difficulties in reading and understanding ray diagrams, especially when they are immediately introduced and students are not systematically supported in the abstraction process $[90,91]$. Many learning difficulties originate from "the coupling of their prior experience with an incomplete understanding of the formal representations" [90].

Ray diagrams may be seen as a simplification at the cost of understanding. Usually students are unaware that ray diagrams are based on a selection of possible light paths, so they typically consider isolated paths of light and tend to lose sight of the whole phenomenon. This in turn hinders conceptual understanding of key concepts like image formation and how optical components (lenses, mirrors, etc.) interact with propagating light [92,93]. Figure 7 contrasts representations with light rays and with diverging light beams. This figure illustrates quite well why students tend to believe, for example, that only half of the image will be visible if the upper half of the lens is covered (G1) [17].

The optics curriculum, on the other hand, does not begin with ray diagrams, but rather with discussion about the propagation of light and the concept of vision. In pictorial representations, propagating light is represented by conical 


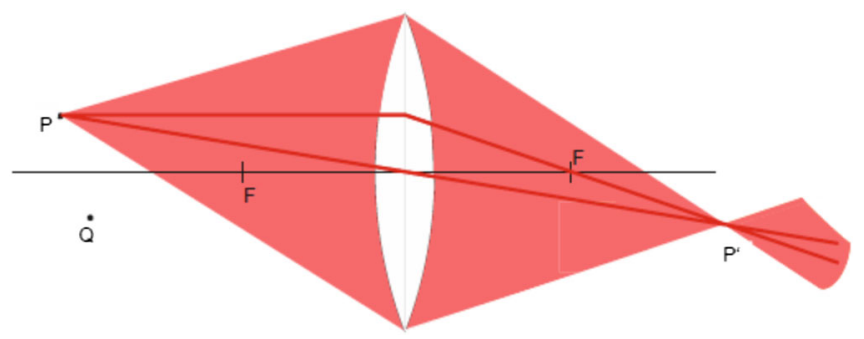

FIG. 7. The propagation of light from a pointlike light source represented by light rays and diverging light beams.

light beams starting from a light source (see Fig. 8). There is evidence that this kind of representation is in good accordance with students' real life experience (G7). Pictorial representations of light as idealized light rays are introduced at a later stage of the curriculum. This procedure is based on implications from research on multiple representations; namely, there is evidence that learners can use their prior knowledge of one representation to build understanding of a second representation [86]. Depending on the context, light rays and light beam representations are used alternately or together in order to establish representational coherency and to gain deeper conceptual understanding. Another implication of research on multiple representations is taken into account. When learners use multiple representations to construct deeper understanding, they need to relate representations to one another [86]. This procedure is not only in resonance with general design principle G7, but also with general design principle G5 as it considers the individual perception and gradually integrates it into more abstract principles.

So, when the pictorial representation of light rays is introduced, the model character of light rays is explicitly discussed and the relation to the observable phenomenon as a whole is made.

\section{4. (DS4) A point-to-point mapping model is used to introduce image formation}

The previously discussed domain specific design principle (DS3) is strongly related to the main idea of (DS4). Image formation is a very challenging topic for students, especially when its explanation is based on the use of standard ray diagrams only, which are typically overrepresented in conventional instruction [95]. In traditional

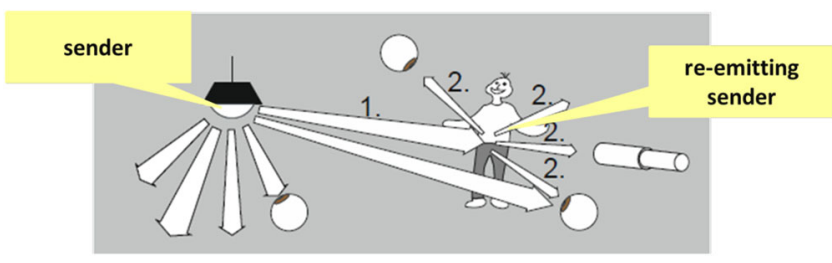

FIG. 8. Categorization of visible objects as sender (primary light source) or reemitting sender (secondary light source) [94].

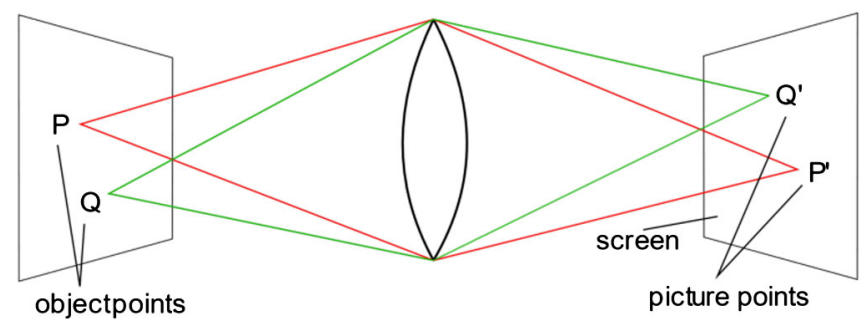

FIG. 9. Point-to-point mapping model.

school settings, teachers tend to overcome the conceptual complexity by providing students with recipelike instructions on how to construct an image with the help of ray diagrams. "[T]he more basic questions of why and how images are formed are not properly addressed." [95].

As the optics curriculum is aligned to students' learning needs, image formation is not immediately formalized by the use of ray diagrams, due to several reasons discussed earlier, like a desire to establish representational coherence (G7) $[84,86]$. We introduce a point-to-point mapping model, based on the point-to-point correspondence (see Fig. 9) between an object and its optical image: A visible, extended object is conceptualized as an arrangement of many luminous points, each of them emitting diverging light bundles. Optical systems like lenses converge these light bundles to an image point. Ray diagrams are introduced at a later part of the curriculum and there, the one-to-one correspondence between object points and picture points is emphasized again.

5. (DS5) Whenever possible, learning paths start from subjectively perceived phenomena. In a second step, these perceptions are integrated in the objective system of physics. Students are repeatedly stimulated to interpret their subjective perception and experiences of optical phenomena from the scientific perspective of physics

As discussed in general principle (G5) on a more general level, individual experiences and scientifically oriented views on these experiences are systematically linked with the aim to increase the status of the scientifically adequate concepts. The following strategy is put into practice wherever possible: First, optical phenomena are investigated in order to explain simple relations between the physical quantities or concepts. Usually, this is done by tracking the path of light from the light source via optical systems to the observer [55,70]. Only then, traditional ray diagrams are constructed and finally related to the initial subjective perceptions.

\section{CYCLES OF INTERVENTION AND EVIDENCE-BASED REDESIGN: THE EXAMPLE OF A CURRICULUM FOR INTRODUCTORY OPTICS}

At the core of each DBR project lies the cyclic and iterative process of design-intervention-redesign: the 
implementation of the current version of a TLE is analyzed and the findings guide the redesign of the TLE. In the development cycle (see Fig. 3), this process finally leads to some kind of artifact that is relevant for school practice and provides evidence-based approaches to address the initial practical problem. In the research cycle, the iterative process results in the refinement of the design principles that frame local and domain specific instruction theories.

Physics education research frequently aims at finding out whether students achieve a certain level of conceptual understanding due to an intervention. DBR pursues additional goals. It seeks to find out if intended learning processes are triggered by the teaching and learning environment, if students follow the conjectured learning paths, and which instructional elements support and/or hinder domain specific learning. Deeper insights into students' domain specific reasoning can, however, only be achieved if the actual processes of students' learning are analyzed in learning process studies. In order to design coherent research, DBR uses different qualitative methods for the analysis of learning processes depending on the research questions and settings [34] (e.g., student interviews, think aloud studies, or teaching experiments $[96,97])$. These methods are mainly used on an individual student level or in small groups and help to evaluate and redesign individual, distinct segments of the TLE.

At the same time, it is necessary to analyze the implementation of the full curriculum in real classroom settings: On one hand, learning is socially situated (Sec. III A), thus social interaction within a classroom may influence the implementation of the curriculum and the intended learning processes. As such, this interaction effect must be taken into account in the process of curriculum development. On the other hand, it is important to optimize the sequencing of the subtopics within a curriculum (Sec. III C). This is not practical in studies with single students due to the length of a curriculum. Here, the implementation in real classroom settings in combination with feedback tools like lesson log books, interviews, and questionnaires can contribute important information for the processes of redesign and validation.

In what follows, we will illustrate the DBR procedure using the concrete example of our curriculum for introductory optics at the middle school level, which was developed over a period of six years. The findings reported in this section refer to the current status of the curriculum, after 78 teaching experiments and 116 student interviews had been carried out in the course of the iterative design process. It is important to mention, however, that the process of curriculum design is never really finished, and must be seen as a work in progress-new research findings and practitioners' feedback constantly provide potential for improvement.

Initially, the perceived practical problem-Austrian students' weak conceptual understanding of introductory optics at the end of middle school—was analyzed in more detail to extract specific deficits. Namely, Austrian students' conceptual understanding of basic optics concepts was tested with a two-tier concept test [98] in a national online survey $(n=3122)$ [17] (see Fig. 4, cycle 0$)$. The analysis of these results provided more detailed insights into the main conceptual problems and served as a roadmap for the curriculum design.

In the next step (Fig. 3, heuristic level) we designed a full draft version of the curriculum that meets the requirements of our national syllabus for year 8. First, we specified the sequencing of relevant concepts of introductory optics. For each of these subtopics, hypothetical learning trajectories and conjectured learning processes were identified following the process model of educational reconstruction (Sec. III C) and the previously defined design principles (Sec. IV). The instructional elements generated in this way were then translated into students' text, tasks, and experiments, which were given to three middle school teachers to obtain first feedback.

As a next step, the DBR model suggests trying the draft in interventions (see Fig. 3, empirical level). To this end, the introductory chapter of the students' text was introduced in a year- 8 class. The students were asked to give feedback on the students' text on two levels, on the content level and on the level of representations (text, pictures, etc.) (Fig. 4, cycle I). After incorporating this feedback, learning processes stimulated by the introductory part of the TLE were investigated with the help of teaching experiments $[99,100]$. As a result, the first chapter of the course was thoroughly modified and some minor global changes were made.

The preliminary version of the full curriculum was implemented in a year- 8 physics class during the span of 22 lessons (see Fig. 4, cycle II). Students' performance was tested in a pre- post-test design, artifacts (e.g., students' notebooks, lesson log book lead by the teacher) were collected, a teacher interview was conducted and student feedback was collected. General weaknesses of the curriculum could be identified by the triangulation of these data.

The following iterations of the design process focused on these weaknesses, which were treated as either new or modified practical problems in the model of DBR (see Fig. 3, empirical level). All sections of the curriculum that were reported as problematic, either by the teacher or the students, were investigated one after another. In other words, parts of the curriculum that caused any kind of practical problem in a school setting initiated a new iteration of the DBR process. This was done in different types of learning process studies depending on the type of practical problem identified. Figure 4 gives an overview of all main design cycles of our project. Each box symbolizes either a design cycle of the full curriculum (Fig. 4, cycles: II, VII, VIII) or a subtopic specific design cycle (Fig. 4, cycles: I, III, IV, V, VI, A, B, C, D). 
As the arrangement of the boxes in vertical and horizontal directions illustrates, the subtopic-specific design cycles were executed either one after another (roman numbers I through VIII in Fig. 4) or in parallel (capital letters in Fig. 4).

The findings of all the previous subtopic-specific design cycles were used for the redesign and this redesigned version was again implemented in an authentic school setting (see Fig. 4, cycle VII). Many research results achieved in the project have already been reported in different papers and so they are here only briefly referred to $[9,10,17,56,57,94,96-104]$. Again, at the end of cycle VII, students' performance was tested in a pre- post-test design, a teacher interview was conducted and student feedback was collected. Based on these findings, the curriculum was redesigned again. This current version of the curriculum was then tested in large scale in authentic school settings in cycle VIII (see Sec. VIB).

\section{LOCAL INSTRUCTION THEORIES AND THE EFFECTIVENESS OF THE OPTICS CURRICULUM}

The process of design-intervention-revision as outlined in the previous section has a theory-generative dimension. The initial set of theory-driven and evidence-based domain specific design principles is refined in response to data collected during successive rounds of implementation as outlined in Sec. V. This procedure results in local, domain, and even topic-specific theories about teaching and learning.

We introduced domain specific design principles as localization of general design principles. General design principles build the overarching theoretical frame, they characterize the general approach in terms of learning theories and conceptual change strategies. Domain specific design principles are local as their form depends on a number of factors specific to the creation context of a curriculum. This section presents the refined domain specific design principles (referred to as DSrev) and a selection of new, additional domain specific design principles (referred to as DSadd). In addition, it summarizes the evaluation of the current version of the curriculum in authentic school settings.

\section{A. Local instruction theory about teaching and learning introductory optics}

This section summarizes empirical findings related to the initial design principles and discusses their revision. In general, a local instruction theory can be regarded as a collection of consistent principles that offer ideas about learning processes and factors supporting these learning processes. The initially generated set of design principles of this project belongs to such a category of principles. They can be treated as hypotheses on teaching and learning introductory optics. In the course of iterative cycles of implementation, they are tested and where necessary refined (theory-driven and theory-generative aspects of DBR).

For the optics curriculum, most of these initial design principles were validated empirically. Some principles needed to be refined on an empirical basis as we will discuss in this section. Refined and added domain specific design principles again echo general design principles. In general, domain specific design principles are also in harmony with each other. However, teaching experiments revealed problematic instructional elements that could not be redesigned without lowering the status of a certain design principle (see DS10add). Collectively, they form a refined version of a local instruction theory on teaching and learning introductory optics. Because of the limited space of this paper, this section will only report a selection of additional principles and refinements of already discussed domain specific design principles that were deduced from empirical findings within the DBR process.

\section{1. (DS2rev) The term light source is replaced by the term sender. This term has two subcategories: emitting sender and reemitting sender}

It was necessary for us to refine the initial principle slightly, since students did not conceptualize the terms sender and reemitting sender on the same hierarchical level (G1). So, we now introduce the term sender as a general description. Afterwards two subcategories are introduced: emitting sender and reemitting sender. These terms better support students in conceptualizing appropriate ideas about the visibility of objects. The term sender is an umbrella term for both and thus higher in hierarchy.

The results which led to this change were gathered in teaching experiments, where students rejected the original names given to the two categories of primary and secondary light sources. A student suggested the word pair emitting sender and reemitting sender (G7). In the next cycle of teaching experiments this change was validated by students [97].

\section{2. (DS6add) The topic of color phenomena, which is conventionally placed at the end of introductory optics in middle school, is treated right after the topic of vision and visibility of objects}

Teaching experiments in the DBR project on introductory optics for middle school showed that the introduction of the SER mechanism [see domain specific design principle (DS1)] was quite successful in promoting students' conceptual understanding. For many students, however, it was unsatisfactory that they were only able to explain the visibility of objects (reemitting sender) and not why they appear in a certain color [99]. Responding to students' interests, we changed the curriculum on the macrolevel and introduced color phenomena right after the SER (sender-emission-receiver) and the SESR (senderemission-scattering-receiver) model (G8). This change in 
sequencing proved to work out fine in interventions in the classroom setting.

\section{3. (DS7add) The process of absorption and selective reemission is stressed as the key mechanism of color phenomena and body color. Pictorial representations mirror all subprocesses}

As (DS6add) points out, color phenomena are introduced together with the SESR model stating that we perceive an object in a certain color because we receive certain spectral colors from this object. Teaching experiments in the DBR project showed that middle school students found it tricky to deduce this process from conventional forms of representation. Hence, we asked year- 8 students who were familiar with this concept to draw this process in a way that would support their peers' understanding (G9) [87]. Their drawings were categorized and synthesized into one representation that demonstrates selective absorption as well as selective reemission (reflection), as shown in Fig. 10: The conical white arrow represents light beams that reach the object permanently. The wiggly arrow entering the object represents the selective absorption part. The green arrow leaving the object represents the reemitted light. Compared to the white arrow, this arrow is intentionally smaller to represent the selectiveness of the process and the conservation of light energy. In addition, the motto "From nothing, nothing can come" is actualized (G4), as the observer perceives only an image of the object if light enters the visual system as shown in Fig. 10.

This type of representation was reported by students to be very helpful in teaching experiments and in interventions in school settings $[94,96]$.

\section{4. (DS8add) White light is represented as white in pictures}

Teaching experiments and student interviews within the DBR project replicated the familiar problem that "the kind of light physicists define as white light is usually conceptualized as ordinary light, 'normal light' (Feher \& Meyer,

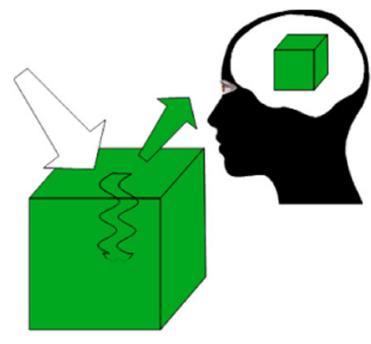

(a)

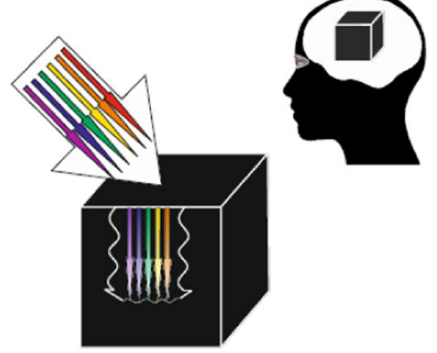

(b)
FIG. 10. (a) Pictorial representation of selective absorption and selective reemission. Body color conceptualized based on the SESR mechanism. (b) Pictorial representation of selective absorption and selective reemission with "black objects."
1992) or simply as light." [9]. When asked for a description of light (which is usually related to daylight or sunlight), students in our study did usually not mention the technical term white light, neither did they attribute the characteristic white. They rather associated yellow or yellowish as key features of light. As the source of their conceptions, students mentioned conventional pictorial representations of light from the sun or from other familiar light sources (light bulbs, flash lights, etc.), in which light is generally represented as yellow (G1) $[9,96]$. In the first version of our curriculum materials, we also represented white light with yellow beams. It was actually quite embarrassing for us to have fallen in this trap. Above this, it was quite challenging to modify all pictures accordingly. In general, it is not trivial to represent white light on white paper. In the later versions of the curriculum, we represent white light with white beams or rays on a gray background (see Fig. 8) or on a white background (see Fig. 6). Teaching experiments showed that visual representations contrasting white and yellow light stimulate awareness that daylight or sunlight is different from yellow light.

\section{5. (DS9add) The curriculum provides learning experiences that support students in understanding the difference between white and yellow light}

As mentioned in (DS8add), learners tend to have problems in conceptualizing the difference between yellow light and white light. However, without a solid understanding of white light, it is difficult to understand body color. In instruction, characteristics of yellow light may be cognitively activated and attributed to daylight or sunlight (white light). If so, it is not plausible for students why daylight or sunlight should be split up into the spectral colors [9]. We developed a simple experiment to help students understand white light (see Fig. 11).

When light (white light) is beamed on a surface that is white under white light by definition (e.g., white paper ISO11475:2004), we can observe a whitish spot on this surface. When the same thing is done with yellow light, we can observe a yellowish spot on this surface as Fig. 11 shows. So, a white light spot on a piece of white copy paper

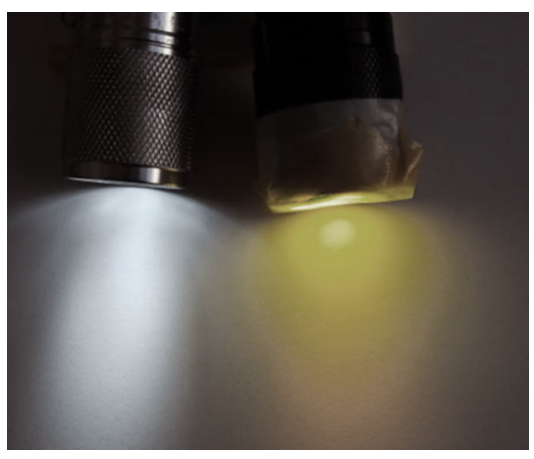

FIG. 11. Experiment for distinguishing yellow and white light. 
proves that the incident light is white, a yellowish light spot proves that the incident light is yellow. For learners it is easy to handle this experiment and to investigate the light color of different light sources (G2, G5) [96].

\section{6. (DS10add) The content structure of the topic body color is aligned to learners' needs on the mesolevel}

In the first version of the optics curriculum, the instruction on the spectral composition of white light was unable to increase the status of the intended key ideas. This instructional element challenged us a lot, as we tried several modifications without any success. In the end, we decided to consult experts. In an expert discussion with physics education researchers, university lecturers of physics education, and physics teachers, audio transcripts of the teaching experiments were analyzed and discussed. The experts suggested to change the content structure on the mesolevel (G8). A traditional content structure that starts with the keyidea "white light can be split up" [see Fig. 12(a)] may activate alternative conceptions about white light as outlined in DS8add and DS9add instead of increasing the status of intended concepts.

Based on this hypothesis, we restructured the sequence of key ideas as shown in Fig. 12(b) and achieved good results in teaching experiments [9].

In this context we had to lower the priority of general design principle G3. While the original content structure followed a continuous conceptual change strategy (G3), the new context structure was based on cognitive conflict. In the original content structure preknowledge about rainbows was activated as a relevant knowledge element. The new approach was based on an experiment showing that red and green light can be mixed and results in yellow light. This causes cognitive dissonances as students usually know only crayons or watercolors and there red and green add up to a brownish black.

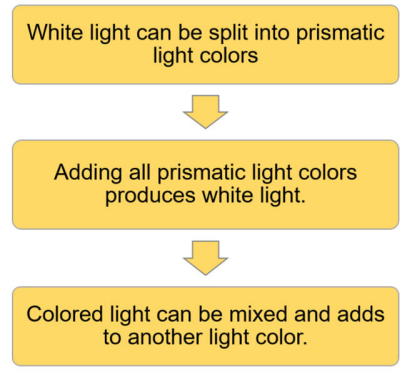

(a)

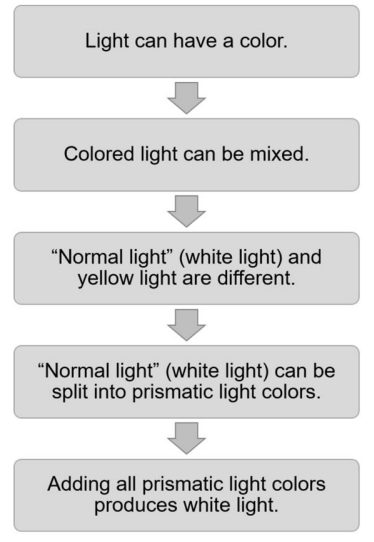

(b)
FIG. 12. Spectral composition of light: (a) traditional content structure and (b) new content structure.
7. (DS11add) The term color is replaced by light color when the physical characteristics of light (wavelength) are addressed and by material color when a material object with a certain reflection characteristic is addressed

Interviews in the course of the DBR project revealed that students usually associate color particles with the term color $[100,104] .{ }^{2}$ This is not very surprising, as from childhood we are confronted with material objects (crayons, watercolors, etc.) which are called colors. In contrast, students have hardly any experience in mixing light beams that appear in different colors ("light colors"). Therefore, the term color may activate notions that are not very helpful for understanding color phenomena as related notions usually operate on the material level of paint particles (G1). In our curriculum, middle school students as well as their teachers appreciated the alternative verbal representations light color and material color as they support students on a conceptual level in distinguishing processes usually labeled as additive and subtractive color mixing (G7).

\section{8. (DS12add) The difference between light and matter is stressed in the curriculum. It is anchored by the motto "light is different"}

From research, it is well known that students interpret light as a substance (G1) [105]. This alternative conception blocks the understanding of other key ideas of optics. Students believe, for example, that light propagates less far from a primary light source during the night than during the day. As a reason they frequently mention that the daylight blocks the light of other sources [98]. Another issue that causes confusion is the mixing of two light beams. In the curriculum, we explicitly discuss and stress one difference between light and matter: A certain place can only be occupied by one material object at a time. On the other hand, if the light of one source propagates through a certain area in space, light from another source can propagate at the same area in space at the same time. This key idea is anchored with the motto "light is different" (G4).

\footnotetext{
${ }^{2}$ What we actually mean when we talk about light color is the color impression we get of a beam of light that hits a white surface. In German, there is one term "Farbe" that stands for both: the color of a beam of light (in short in our paper: light color) and the color of material objects like paint particles (in short in our paper: material color). This fact-one term with two different meanings-is confusing for students when it comes to color mixing, as they do not distinguish whether color in terms of light (additive mixing) or in terms of paint particles (subtractive mixing) is addressed. Usually they just think of the latter. So, the idea was to specify what we mean in our curriculum when we say color: light color ("the color of" a light beam) or material color (the material aspect of color, the color of material objects or the color of the paint particle). So, for us, the latter denotes macroscopic, material objects which we perceive in a certain color under white light.
} 


\section{9. (DS13add) The concept of kinesthetic astronomy [106] is used to teach the phases of the moon}

The concept of kinesthetic astronomy involves a series of simple body movements of learners to provide insight into celestial motion and "how these motions influence what we see in the sky at various times of the day and year" (G2) [106]. The teachers involved in the first field implementation of our curriculum criticized the chapter on the phases of the moon due to its very conventional approach. According to them, students were not supported in understanding the most important concepts. They gave feedback that the students especially struggled with the special aspect that two-dimensional pictures needed to be interpreted while the process is three dimensional. This feedback is consistent with research regarding the use of multiple representations and the difficulty multiple representations may cause learners in certain contexts $[107,108]$. It was suggested to integrate the concept of kinesthetic astronomy in the curriculum for the section on the phases of the moon. In so doing, learners were able to gain knowledge from one representation that has an enactive characteristic, before additional iconic representations were introduced. According to feedback of later implementation of the curriculum that utilized this holistic approach, the strategy of "applying the understanding of one representation to interpret the other representation" [109] was successful in supporting student learning (G7).

\section{0. (DS14add) When students explore image formation with plane mirrors, they first focus on the image formation of external objects before their own mirror image is treated}

Teaching experiments within the DBR project [103] revealed that image formation with plane mirrors is very difficult for students, as consistent with prior PER findings [61,110-112]. Most students have the deeply rooted misconception that a plane mirror flips right and left (G1). This idea seems even to be reinforced when they explore image formation by observing their own mirror image. In this case, the dual role of the student as both observer and mirrored object adds additional complexity to the situation. When we observe our own mirror image, we believe that we are facing ourselves in the way we would face a person that stands opposite to us, so to speak, a person that looks out of the mirror. Actually, we perform a horizontal flip mentally without noticing. This causes problems for learning processes with plane mirrors. If students explore images of objects that are positioned between the mirror and the observer first, the intended concept is strengthened. The understanding of their own mirror image can be developed on this basis.

\section{B. Large scale evaluation of the curriculum for introductory optics in school settings}

The previous sections were dedicated to the theory-intopractice aspect of curriculum design: Using the example of our curriculum for introductory optics, we presented the process of the curriculum development and its theoretical underpinnings as well as generated theories about teaching and learning introductory optics at middle school level. Finally, we will briefly focus on the empirical results of our curriculum. As illustrated in Sec. VI A, the iterative process of design-intervention-revision was based on empirical findings in teaching experiments and other interventions in authentic school settings, which were reported in numerous publications [10]. However, we want to give a picture of the full project, which also includes empirical results of the implementation in school settings. Therefore, we report the results of the first full implementation of the curriculum in its current form in authentic school settings in five year-8 middle school classes in Austria.

The teachers of these classes were provided with the curriculum materials. However, they were not explicitly introduced to the curriculum, nor were they given any additional details about the theoretical background of the curriculum. Only a short informal meeting was scheduled individually with each teacher before the intervention. There, the teachers were asked to keep lesson log books to document each lesson and to obtain regular student feedback. Impressions collected during the work with our curriculum were discussed during a second short meeting with the teachers afterwards.

Students' learning gains were measured in a pre-post design using a two-tiered multiple-choice test on conceptual understanding in introductory optics $[17,98,102]$. The idea was not only to determine students' learning gains caused by our intervention, but also to compare their learning outcomes with that of traditionally instructed classes according to the national year- 8 physics syllabus. Therefore, conceptual understanding was also tested in 16 comparable Austrian middle school classes. Additionally, the teachers of these 16 year- 8 classes were asked to fill in a lesson $\log$ book, which requested information about their optics instruction, like the topics covered, the number of lessons taught, the materials used, etc.

Data were analyzed with IBM SPSS 22 . The internal consistency of the test was determined by Cronbach's $\alpha$ [113]. The scores of Cronbach's $\alpha$ were 0.57 for the pre-test and 0.70 for the post-test. The low scores for the pre-test are not surprising due to the floor effects of students' performance before the intervention. The scores for the post-test are acceptable, especially when we consider the two-tiered structure of the items. We only analyzed cases with completely filled in pre-tests and post-tests. Based on these restrictions, the intervention group consisted of 93 students [49 female, 40 male, 4 not assignable; mean age $M=13.8 \mathrm{yr}(\mathrm{SD}=0.571)]$ and the baseline group of 393 [169 female, 196 male, 28 not assignable; $M=13.99 \mathrm{yr}$ $(\mathrm{SD}=0.58)]$. The groups did not show any significant difference according to their performance in physics, which was compared based on their grades $(1=$ excellent, 
$5=$ fail). The average grade in physics was $M=2.15$ $(\mathrm{SD}=0.99)$ in the intervention group and $M=2.23$ $(\mathrm{SD}=1.077)$ in the baseline group. A Mann-Whitney U-Test [113] — a nonparametric test to compare two sample means of ordinal data-was performed. It showed no significant difference between the groups.

For the students who were instructed with our curriculum a $t$-test on paired differences [113] was performed to determine whether the mean difference between the performance in the pre-test and in the post-test of the same students is zero. The results of the test on paired differences indicates a highly significant difference between the mean pre-test and post-test scores of the intervention group $[t(92)=-11.855, p<0.001]$. Cohen's $d$ was calculated to illustrate the effect of the intervention, and shows a big effect $(d=1.31)$ [113].

A comparison of the pre-tests and post-tests of the students who were instructed with our curriculum and the students who were traditionally instructed was carried out. A $t$-test on independent samples [113] was conducted. It compares the means of different groups of students that were assigned to different treatments. In our case the postinstructional sum scores of the intervention group and the baseline group were compared. The results show that the students of the intervention group performed significantly better in the postoptics concept test $[t(484)=10.197, p<0.001]$. The results of the Levene test [113], which is in general used to test the null hypothesis that the variances of the different groups are equal, report the equality of variances $(F=0.329$, sig $=0.566)$. The overall effect size due to the treatment is $\operatorname{big}(d=1.18)$. A closer analysis on item level shows that the students of the intervention group outperform the baseline group on a highly significant level in items where the mastery of the SER model is helpful. More detailed findings are reported in Ref. [10].

\section{CONCLUSION: DESIGN-BASED RESEARCH SUPPORTING THEORY INTO PRACTICE}

As we have tried to show in this paper, the development of theory-driven and evidence-based curricula is a challenging and time-consuming business. Challenging as there are instances when carefully designed instructional elements do not work at all and you have to start from scratch again (see Sec. VIA). This and the fact that learning processes are split up to very small sequences for analysis makes it time consuming. Another challenging and timeconsuming component is the organizational dimension as DBR works in authentic school settings. This is particularly the case if one prioritizes the utility of the curriculum for practitioners as we have done, instead of being content with demonstrating success in ideal conditions that do not mirror real school contexts [114].

We recommend design-based research as one possible research agenda to improve the existing teaching practice in middle school physics classrooms. This approach provides theoretical guidelines that make the process of curriculum design transparent without being too rigid to ignore diverse conditions and needs of authentic school settings. In the particular case of the optics curriculum, we identified the relevant theoretical aspects underpinning the design process itself on a metalevel as outlined in Sec. II and operationalized the single steps we undertook. In Sec. IV we outlined the theory-into-practice aspect on the operative level of curriculum design. The theories outlined in Sec. III are the basis for the design process of our curriculum on the level of the intended learning processes in optics. Sec. IV showed how these theoretical aspects were translated into two types of design principles: The general as well as the domain specific design principles. These principles guided the curriculum design as hypotheses about the domain specific learning processes. To be clear, the actual form of a curriculum is defined not only by the design principles; rather, it is also shaped by the curriculum designer's experience and creativity. Nevertheless, the operationalization of the first version of the design principles made it possible to identify critical aspects during the implementation of different iterations of the curriculum as illustrated in Sec. V. Based on the empirical findings from learning process studies, we were able to refine the original principles as outlined in Sec. VA. For example, it very soon became clear to us that the term sender was way more general for learners than the term reemitting sender. Through this, we understood that students could not easily discriminate between those two. The redesign, to introduce sender as a general category with two subcategories, enhanced students' learning drastically.

One perhaps may see this as a trivial point. For us, however, this is a point at the core of our understanding of a DBR-based approach to curriculum development. As we found out, even slight changes in the use of ideas, terms, or pictorial representations can change the learning significantly. It seems that teaching and learning arrangements are chaotic in the sense that even slight differences in design may lead to an enormous difference in the outcomes. The use of the design principles made such effects visible and they helped us in refining the local instruction theory on teaching and learning.

The empirical results on the implementation of the full curriculum in authentic school settings indicate that the curriculum in its present form, having undergone several changes and adaptions, is qualified for further use. The analyses of students' learning outcomes reveal that students instructed with our curriculum improve their achievement significantly and clearly outperform traditionally instructed students. This is remarkable, as the teachers who implemented our curriculum in their classes were not informed of the underlying framework and theoretical considerations of the course.

To sum it up, our DBR approach to curriculum design resulted in valuable findings and products on both levels, on the development and on the research level. First, we 
were able to develop ready to use curriculum materials that are appreciated by teachers and students. And above all, we could show that our curriculum materials promote learning of introductory optics significantly better than traditional instruction does.

Our major contribution to research is to shed light on a systematic process of how design principles are deduced and practically applied in the creation of a curriculum. Additionally, we show how they are refined in response to data collected during implementation. We have also uncovered how and why design decisions were taken and how they were translated into curriculum material. In addition, we outlined the different types of interventions (learning process studies, teaching experiments, field studies, ...) that helped us to test the efficiency of the curriculum and the materials that go with it. Generally speaking, this paper contributes to the still existing gap $[3-5,7,8]$ on how learning theories can systematically shape curricula.

The detailed description of this theory-into-practice aspect and of related challenges (see Sec. VI A) shall also assist other collectives of PER researchers and teachers in their curriculum design endeavors. We believe our approach can be easily transferred to other curriculum design projects, due to our experiences in several curriculum design projects following this approach.

Lessons learned from our optics project can be summarized as follows: Identify and analyze the initial practical problem(s). Invest enough time in literature research and preparatory theory work. It will pay off. Verbalize the design principles in sufficient detail so that they are comprehensible even for external persons. It is not enough to simply have the design principles in mind. The design principles function as a heuristic for each design decision. Be aware that you cannot do everything at once. Start with first small steps and develop the curriculum and the design principles iteratively and consider them mutually. Align your evaluation tools well to the objectives of the curriculum project. Do not lose sight of the initial practical problem. Use the data collected during different phases and types of implementation to rethink and refine design principles and already existing instructional elements. Find critical friends. Cooperate with open-minded and researchoriented teachers and appreciate their practical wisdom.

All in all, we interpret these outcomes as a hint that a theory-into-practice approach as inherent in DBR can bring us closer to our goal of enhancing the quality of middle school physics instruction by finding informal channels of bridging the gap between research findings and school reality.

\section{ACKNOWLEDGMENTS}

The authors acknowledge the financial support by the University of Graz (GZ: 39/23/111b ex 2020).
[1] V. Spatz, T. Wilhelm, M. Hopf, C. Waltner, and H. Wiesner. Teachers using a novel curriculum on an introduction to Newtonian mechanics: The effects of a short-term professional development program, J. Sci. Teach. Educ. 30, 159 (2019).

[2] C. Haagen, J.-P. Burde, M. Hopf, V. Spatz, and T. Wilhelm, Using the electron gas model in lower secondary schoolsa binational design-based research project, in Concepts, Strategies and Models to Enhance Physics Teaching and Learning (Springer, New York, 2019), pp. 3-12.

[3] F. Goldberg, V. Otero, and S. Robinson, Design principles for effective physics instruction: A case from physics and everyday thinking, Am. J. Phys. 78, 1265 (2010).

[4] F. Goldberg, E. Price, S. Robinson, D. Boyd-Harlow, and M. McKean, Developing the learning physical science curriculum: Adapting a small enrollment, laboratory and discussion based physical science course for large enrollments, Phys. Rev. ST Phys. Educ. Res. 8, 010121 (2012).

[5] M. C. Linn, P. Bell, and E. A. Davis, Specific design principles: Elaborating the scaffolded knowledge integration framework, in Internet Environments for Science Education, edited by M. C. Linn, E. A. Davis, and P. E. Bell (Lawrence Erlbaum Associates Publishers, 2004).
[6] R. Duit, H. Schecker, D. Höttecke, and H. Niedderer, Teaching physics, in Handbook of Research on Science Education, edited by N. G. Lederman and S. K. Abell (Routledge, London, 2014), pp. 434-456.

[7] E. Kuo and C. E. Wieman, Toward instructional design principles: Inducing Faraday's law with contrasting cases, Phys. Rev. Phys. Educ. Res. 12, 010128 (2016).

[8] Y. Kali, The design principles database as a means for promoting design-based research, in Handbook of Design Research Methods in Education: Innovations in Science, Technology, Engineering, and Mathematics Learning and Teaching, edited by A.E. Kelly, R. A. Lesh, and J. Y. Baek, (Routledge, London, 2008), pp. 423-438.

[9] C. Haagen-Schützenhöfer, Students' conceptions on white light and implications for teaching and learning about colour, Phys. Educ. 52, 044003 (2017).

[10] C. Haagen-Schützenhöfer, Development of research based teaching materials: The learning output of a course for geometrical optics for lower secondary students, in Key Competences in Physics Teaching and Learning, edited by T. Greczyło and E. Dębowska (Springer, New York, 2017), pp. 105-116.

[11] The Design-Based Research Collective, Design-based research: An emerging paradigm for educational inquiry, Educ. Res. 32, 5 (2003). 
[12] J. Confrey, The evolution of design studies as methodology, in The Cambridge Handbook of the Learning Sciences, edited by R. K. Sawyer (Cambridge University Press, Cambridge, New York, 2006), pp. 135-152.

[13] S. Prediger, K. Gravemeijer, and J. Confrey, Design research with a focus on learning processes: an overview on achievements and challenges, ZDM Math. Educ. 47, 877 (2015).

[14] M. Fullan and A. Pomfret, Research on curriculum and instruction implementation, Rev. Educ. Res. 47, 335 (1977).

[15] S. Barab and K. Squire, Design-based research: Putting a stake in the ground, J. Learn. Sci. 13, 1 (2004).

[16] P. Cobb, J. Confrey, R. Lehrer, and L. Schauble, Design experiments in educational research, Educ. Res. 32, 9 (2003).

[17] C. Haagen-Schützenhöfer and M. Hopf, Standardization in physics-first steps in the Austrian Educational System, in E-Book Proceedings of the ESERA 2011 Conference: Science Learning and Citizenship, edited by C. Bruguière, A. Tiberghien, and P. Clément (European Science Education Research Association, Lyon, France, 2012).

[18] L. Ejersbo, Design and redesign of an in-service course, Ph.D. thesis, Kopenhagen, 2007.

[19] L. Ejersbo, R. Engelhardt, L. Frølunde, T. Hanghøj, R. Magnussen, and M. Misfeldt, Balancing product design and theoretical insights, in Handbook of Design Research Methods in Education: Innovations in Science, Technology, Engineering, and Mathematics Learning and Teaching, edited by A. E. Kelly, R. A. Lesh, and J. Y. Baek (Routledge, London, 2008), pp. 149-163.

[20] D. Shaffer and K. Kipp, Developmental Psychology: Childhood and Adolescence (Wadsworth Cengage Learning, Belmont, 2013).

[21] B. Overwien, Stichwort: Informelles Lernen, Z. Erziehungswissenschaft 8, 339 (2005).

[22] Mental Models, edited by D. Gentner and A. L. Stevens (Psychology Press, New York, 2014).

[23] G. Posner, K. Strike, P. Hewson, and W. Gertzog, Accommodation of a scientific conception: Toward a theory of conceptual change, Sci. Educ. 66, 211 (1982).

[24] S. Vosniadou and W. Brewer, Mental models of the earth: A study of conceptual change in childhood, Cogn. Psychol. 24, 535 (1992).

[25] A. Elby, What students' learning of representations tells us about constructivism, J. Math. Behav. 19, 481 (2000).

[26] R. Duit and D. Treagust, Conceptual change: Still a powerful framework for improving the practice of science instruction, in Issues and Challenges in Science Education Research: Moving Forward, edited by K. Chwee, D. Tan, and M. Kim (Springer, London, 2012), pp. 43-54.

[27] T. G. Amin, C. L. Smith, and M. Wiser, Student conceptions and conceptual change: Three overlapping phases of research, in Handbook of Research on Science Education, Vol. II, edited by N. G. Lederman and S. K. Abell (Routledge, New York, 2014), pp. 71-95.

[28] D. Hammer and E. Manz, Odd ideas about learning science: A response to Osborne, Sci. Educ. 103, 1289 (2019).

[29] P. Potvin, Proposition for improving the classical models of conceptual change based on neuroeducational evidence: conceptual prevalence, Neuroeducation 1, 16 (2013).

[30] K. Dunbar, J. Fugelsang, and C. Stein, Do naïve theories ever go away? Using brain and behavior to understand changes in concepts, in Thinking with Data, edited by M. Lovett and P. Shah (Psychology Press, East Sussex, UK, 2007), pp. 193-206.

[31] S. Masson, P. Potvin, M. Riopel, and L. Foisy, Differences in brain activation between novices and experts in science during a task involving a common misconception in electricity, Mind Brain Educ. 8, 44 (2014).

[32] S. Masson, P. Potvin, M. Riopel, L. Foisy, and S. Lafortune, Using fMRI to study conceptual change: Why and how?, Int. J. Environmental Sci. Educ. 7, 19 (2012).

[33] P. Potvin, É. Sauriol, and M. Riopel, Experimental evidence of the superiority of the prevalence model of conceptual change over the classical models and repetition, J. Res. Sci. Teach. 52, 1082 (2015).

[34] P. Hewson, On the interaction of physics with science education research, in Proceedings of the 2016 Physics Education Research Conference, Sacremento, CA, edited by D. L. Jones, L. Ding, and A. Traxler (AIP, New York, 2016), pp. 18-22.

[35] C. Schreiner and S. Sjøberg, The relevance of science education, Sowing the Seed of ROSE (Acta Didactica, Oslo, 2004).

[36] S. Sjøberg and C. Schreiner, The ROSE Project: An Overview and Key Findings (University of Oslo Oslo, 2010).

[37] R. Bybee and B. McCrae, Scientific literacy and student attitudes: Perspectives from PISA 2006 science, Int. J. Sci. Educ. 33, 7 (2011).

[38] B. Drechsel, C. Carstensen, and M. Prenzel, The role of content and context in PISA interest scales: A study of the embedded interest items in the PISA 2006 science assessment, Int. J. Sci. Educ. 33, 73 (2011).

[39] U. Kattmann, R. Duit, and H. Gropengießer, The model of educational reconstruction. Bringing together issues of scientific clarification and students' conceptions, in What-Why-How? Research in Didaktik of biology, $I P N$, Kiel, edited by H. Bayrhuber and F. Brinkman (1998), pp. 253-262.

[40] R. Duit, H. Gropengießer, U. Kattmann, M. Komorek, and I. Parchmann, The model of educational reconstruction-a framework for improving teaching and learning science, in Science Education Research and Practice in Europe, edited by D. Jorde and J. Dillon (Springer, New York, 2012), pp. 13-37.

[41] E. van Dijk and U. Kattmann, A research model for the study of science teachers' PCK and improving teacher education, Teaching Teacher Educ. 23, 885 (2007).

[42] M. Brueckmann, Sachstrukturen im Physikunterricht: Ergebnisse einer Videostudie (Logos, Berlin, 2009).

[43] C. T. Müller and R. Duit, Die unterrichtliche Sachstruktur als Indikator für Lernerfolg-Analyse von Sachstrukturdiagrammen und ihr Bezug zu Leistungsergebnissen im Physikunterricht, Z. Didaktik der Naturwissenschaften 10, 147 (2004). 
[44] T.-R. Sikorski and D. Hammer, Looking for coherence in science curriculum, Sci. Educ. 101, 929 (2017).

[45] D. Hammer, The interacting dynamics of epistemology and conceptual understanding, in Converging and Complementary Perspectives on Conceptual Change, edited by T. G. Amin and O. Levrini (Routledge, London, 2018), pp. 245-252.

[46] R. Duit, Bibliography-STCSE: Students' and teachers' conceptions and science education. Retrieved October 20, 2009, http://archiv.ipn.uni-kiel.de/stcse/.

[47] AAAS strand maps. http://flora.p2061.org/SVGMaps/ v98.3/index.html.

[48] B. Andersson and C. Kärrqvist, How Swedish pupils, aged 12-15 years, understand light and its properties, Int. J. Sci. Educ. 5, 387 (1983).

[49] D. Jones and D. Zollman, Understanding vision: students' use of light and optics resources, Eur. J. Phys. 35, 055023 (2014).

[50] E. Guesne, Light, in Children's Ideas in Science, 1993rd ed., edited by R. Driver, E. Guesne, and A. Tiberghien (Open University Press, Buckingham, 1985), pp. 10-32.

[51] C. de Hosson and W. Kaminski, Historical controversy as an educational tool: Evaluating elements of a teachinglearning sequence conducted with the text "Dialogue on the Ways that Vision Operates", Int. J. Sci. Educ. 29, 617 (2007).

[52] N. J. Selley, Children's ideas on light and vision, Int. J. Sci. Educ. 18, 713 (1996).

[53] H. Wiesner, Schülervorstellungen und Lernschwierigkeiten im Bereich der Optik. Naturwissenschaften im Unterricht-Physik/Chemie 34 (1986), Heft 13, in Schülervorstellungen in der Physik, 2nd ed., edited by R. Müller, R. Wodzinski, and M. Hopf (Aulis, Köln, 2007).

[54] I. Galili and A. Hazan, Learners' knowledge in optics: interpretation, structure and analysis, Int. J. Sci. Educ. 22, 57 (2000).

[55] D. Herdt, Einführung in die elementare Optik, Vergleichende Untersuchung eines neuen Lehrgangs (WestarpWissenschaftsverlag, Essen 1990).

[56] C. Haagen-Schützenhöfer, Theory-Practice Gap: The relevance of students' conceptions for teaching geometrical optics in practice, in Proceedings of ICPE 2013 (Vortrag, Prague, 2013).

[57] C. Haagen-Schützenhöfer, Theory-practice gap: The relevance of students' conceptions for teaching geometrical optics in practice, in Proceedings of the ICPE-EPEC Conference 2013: Active Learning-in a Changing World of New Technologies, edited by L. Dvorak and V. Koudelková (Charles University in Prague, MATFYZPRESS Publisher, Prague, 2014), pp. 144-152.

[58] P. R. L. Heron and L. C. McDermott, Bridging the gap between teaching and learning in geometrical optics: The role of research, Optics Photonics News 9, 30 (1998).

[59] L. Viennot and W. Kaminski, Can we evaluate the impact of a critical detail? The role of a type of diagram in understanding optical imaging, Int. J. Sci. Educ. 28, 1867 (2006).

[60] K. Wosilait, P. R. L. Heron, P. S. Shaffer, and L. C. McDermott, Development and assessment of a research-based tutorial on light and shadow, Am. J. Phys. 66, 906 (1998).

[61] C. C. Chen, H.S. Lin, and M. L. Lin, Developing a two-tier diagnostic instrument to assess high school students' understanding - the formation of images by a plane mirror, in Proceedings of the National Science Council Republic of China, Part D Mathematics Science and Technology Education 12 (2002), pp. 106-121.

[62] A. Mota and J. Lopes, Addition table of colours: Additive and subtractive mixtures described using a single reasoning model, Phys. Educ. 49, 61 (2014).

[63] F. Chauvet, Teaching colour: designing and evaluation of a sequence, Eur. J. Teach. Educ. 19, 121 (1996).

[64] G. Martinez-Borreguero, Á. L. Pérez-Rodríguez, M. I. Suero-López, and P. J. Pardo-Fernández, Detection of misconceptions about colour and an experimentally tested proposal to combat them, Int. J. Sci. Educ. 35, 1299 (2013).

[65] D. Sokoloff, Active learning of introductory optics: Interactive lecture demonstrations and optics magic tricks, in Proceedings of the Tenth International Topical Meeting on Education and Training in Optics and Photonics, edited by M. Nantel (International Society for Optics and Photonics, Bellingham, WA, 2015), p. 966516.

[66] L. Viennot and C. de Hosson, Colour Phenomena and Partial Absorption, MUSE group (More Understanding with Simple Experiments) in the Physics Education Division (PED) of the European Physical Society (EPS), http://citeseerx.ist.psu.edu/viewdoc/download? doi=10.1.1.687.5245\&rep=rep 1\&type=pdf.

[67] W. Jung, Erhebungen zu Schülervorstellungen in der Optik (Sekundarstufe I), Physica Didactica 8, 137 (1981).

[68] W. Jung, Fallstudien zur Optik, Physica Didactica 9, 199 (1982).

[69] C. Schmidt-Roedenbeck, R. Müller, H. Wiesner, D. Herdt, and P. Engelhardt, Unterricht Physik, Opitk III/2. Wölb- und Hohlspiegel, in Spiegelteleskop (Auge, Farben, Aulis, Köln, 2005).

[70] H. Wiesner, P. Engelhardt, and D. Herdt, Unterricht Physik, Optik I: Lichtquellen (Reflexion, Aulis Verlag Deubner \& Co, Köln, 1995).

[71] H. Wiesner, P. Engelhardt, and D. Herdt, Unterricht Physik, Optik II: Brechung, Linsen (Aulis Verlag Deubner \& Co, Köln, 1996).

[72] H. Wiesner, D. Herdt, and P. Engelhardt, Unterricht Physik, Opitk III/1. Optische Geräte (Aulis, Köln, 2003).

[73] E. M. Bardar, E. E. Prather, K. Brecher, and T. F. Slater, Development and validation of the light and spectroscopy concept inventory, Astron. Educ. Rev. 5, 103 (2006).

[74] Re-framing the Conceptual Change Approach in Learning and Instruction, 1st ed., edited by S. Vosniadou, A. Baltas, and X. Vamvokoussi (Elsevier, Amsterdam, 2007).

[75] P. Kirschner, J. Sweller, and R. Clark, Why minimal guidance during instruction does not work: An analysis of the failure of constructivist, discovery, problem-based, experiential, and inquiry-based teaching, Educ. Psychol. 41, 75 (2006).

[76] P. Häussler, L. Hoffmann, R. Langeheine, J. Rost, and K. Sievers, Qualitative Unterschiede im Interesse an Physik 
und Konsequenzen für den Physikunterricht, Z. Didaktik der Naturwissenschaften 2, 57 (1996).

[77] B. Suchán and S. Breit, PISA 2015 Grundkompetenzen am Ende der Pflichtschulzeit im internationalen Vergleich (Leykam, Graz, 2016).

[78] A. Gurria, PISA 2015 results in focus, in PISA in Focus (Organisation for Economic Co-operation and Development, Paris, 2016), Vol. I, https://www.oecd-ilibrary.org/ docserver/aa9237e6-en.pdf?expires $=1600893245 \& i d=$ id\&accname $=$ guest $\&$ checksum $=51699 \mathrm{BB} 0217 \mathrm{~EB} 3 \mathrm{~A} 2 \mathrm{C}$ 65D5CA265BC0EA4.

[79] P. Häussler and L. Hoffmann, Physikunterricht an den Interessen von Mädchen und Jungen orientiert, Unterrichtswissenschaft 23, 107 (1995).

[80] D. Elster, Zum Interesse Jugendlicher an den Naturwissenschaften, Ergebnisse der ROSE Erhebung aus Deutschland und Österreich (Shaker Verlag, Aachen, 2010).

[81] J. Scheid, Multiple Repräsentationen, Verständnis physikalischer Experimente und kognitive Aktivierung: Ein Beitrag zur Entwicklung der Aufgabenkultur, (Logos, Berlin, 2013).

[82] J. Scheid, A. Müller, W. Schnotz, J. Kuhn, and W. Müller, Development of Representational Competence via Cognitive Activating Tasks for Physical Experiments (2010).

[83] Multiple Representations in Physics Education, edited by D. F. Treagust, R. Duit, and H.E. Fischer (Springer, New York, 2017).

[84] J. Scheid, A. Müller, R. Hettmannsperger, and W. Schnotz, Improving learners' representational coherence ability with experiment-related representational activity tasks, Phys. Rev. Phys. Educ. Res. 15, 010142 (2019).

[85] M. Opfermann, A. Schmeck, and H. E. Fischer, Multiple representations in physics and science education-why should we use them?, in Multiple Representations in Physics Education (Springer, New York, 2017), pp. 1-22.

[86] S. Ainsworth, The multiple representation principle in multimedia learning, in The Cambridge Handbook of Multimedia Learning, 2014th ed., edited by R. E. Mayer (Cambridge University Press, Cambridge, England, 2014).

[87] E. H. van Zee, D. Hammer, M. Bell, P. Roy, and J. Peter, Learning and teaching science as inquiry: A case study of elementary school teachers' investigations of light, Sci. Educ. 89, 1007 (2005).

[88] S. Prediger, M. Komorek, A. Fischer, R. Hinz, S. Hussmann, B. Moschner, B. Ralle et al., Der lange Weg zum Unterrichtsdesign. Zur Begründung und Umsetzung fachdidaktischer Forschungs-und Entwicklungsprogramme; Der lange Weg zum Unterrichtsdesign: Zur Begründung und Umsetzung fachdidaktischer Forschungs- und Entwicklungsprogramme (Vol. 5), edited by M. Komorek and S. Prediger (Waxmann Verlag, Münster, München, Berlin, 2013), pp. 9-23.

[89] D. Sokoloff, Active Learning in Optics and Photonics (UNESCO, Paris, France, 2006).

[90] M. Ronen and B. S. Eylon, To see or not to see: the eye in geometrical optics-when and how?, Phys. Educ. 28, 52 (1993).

[91] A. Undreiu, D. Schuster, and B. Adams, Reasoning modes, knowledge elements and their interplay in optics problem solving, AIP Conf. Proc. 1064, 211 (2008).
[92] P. Colin and L. Viennot, Using two models in optics: Students' difficulties and suggestions for teaching, Am. J. Phys. 69, S36 (2001).

[93] D. J. Grayson, Many rays are better than two, Phys. Teach. 33, 42 (1995).

[94] C. Haagen-Schützenhöfer, Lehr- und Lernprozesse im Anfangsoptikunterricht der Sekundarstufe I, in Kumulative Habilitationsschrift, Wien (University of Vienna, Vienna, 2016).

[95] P. Tao, Developing understanding of image formation by lenses through collaborative learning mediated by multimedia computer-assisted learning programs, Int. J. Sci. Educ. 26, 1171 (2004).

[96] C. Haagen-Schützenhöfer, I. Fehringer, and M. Hopf, Akzeptanzbefragung zu Optikunterrichtsmaterialien: Farben, in GDCP Jahrestagung in München 2013: $\mathrm{Na}$ turwissenschaftliche Bildung zwischen Science- und Fachunterricht, edited by S. Bernholt (LIT Verlag, Münster/ New York, 2014), pp. 639-641.

[97] C. Haagen-Schützenhöfer, J. Rottensteiner, and M. Hopf, Akzeptanzbefragung zu Optikunterrichtsmaterialien, in GDCP Jahrestagung in Hannover 2012: Inquiry-based learning-Forschendes Lernen, edited by S. Bernholt (LIT Verlag, Münster/New York, 2013), pp. 431-433.

[98] C. Haagen-Schützenhöfer and M. Hopf, Development of a two-tier test-instrument for geometrical optics, in $E$ Book Proceedings of the ESERA 2013 Conference: Science Education Research for Evidence-based Teaching and Coherence in Learning, edited by Constantinos P. Constantinou, N. Papadouris, and A. Hadjigeorgiou (European Science Education Research Association, Nicosia, Cyprus, 2014), p. 89.

[99] C. Haagen and M. Hopf, Development of teaching materials: a course for geometrical optics for lower secondary students, in Teaching/Learning Physics: Integrating Research into Practice: Proceedings of the GIREP /MPTL Conference 2014, edited by C. Fazio and R. M. Sperandeo-Mineo (University di Palermo, Palermo, 2015), pp. 241-248.

[100] C. Haagen, Simple experiments supporting conceptual understanding of body colour, in Teaching/Learning Physics: Integrating Research into Practice: Proceedings of the GIREP IMPTL Conference 2014, edited by C. Fazio and R. M. Sperandeo-Mineo (University di Palermo, Palermo, 2015), pp. 249-256.

[101] I. Bartosch and C. Haagen-Schützenhöfer, Politische Bildung im Physikunterricht, in Politisches Lernen: Der Beitrag der Unterrichtsfächer zur politischen Bildung, edited by H. Ammerer, R. Krammer, and U. Tanzer (Studienverlag, Innsbruck, 2010), pp. 255-260.

[102] C. Haagen-Schützenhöfer and M. Hopf, Testing students' conceptual understanding in geometrical optics with a two tier instrument, in World Conference on Physics Education 2012, edited by M. F. Taśar (Ankara, Pegem Akademi, 2012).

[103] C. Haagen-Schützenhöfer, Professionalisierung durch Lehren: Lehramtsstudierende lehren und beforschen die Lernprozesse von Schülerinnen und Schülern, in Last oder Lust? Die Rolle der Forschung in der LehrerInnen- 
bildung, edited by K. Soukup-Altrichter and E. Feyerer (Waxmann, Münster, 2014), pp. 89-105.

[104] C. Haagen-Schützenhöfer, A hands-on to teach colour perception: The colour vision tube, Sci. Ed. 8, 191 (2017).

[105] Children's Ideas in Science, 1993rd ed., edited by R. Driver, E. Guesne, and A. Tiberghien (Open University Press, Buckingham, 1985).

[106] C. A. Morrow, Kinesthetic astronomy: The sky time lesson, Phys. Teach. 38, 252 (2000).

[107] S. Ainsworth, The educational value of multiple-representations when learning complex scientific concepts, in Visualization: Theory and Practice in Science Education (Springer, New York, 2008), pp. 191-208.

[108] S. Galano, A. Colantonio, S. Leccia, I. Marzoli, E. Puddu, and I. Testa, Developing the use of visual representations to explain basic astronomy phenomena, Phys. Rev. Phys. Educ. Res. 14, 010145 (2018).
[109] M. Won, H. Yoon, and D. F. Treagust, Students' learning strategies with multiple representations: Explanations of the human breathing mechanism, Sci. Educ. 98, 840 (2014).

[110] F. M. Goldberg and L. C. McDermott, Student difficulties in understanding image formation by a plane mirror, Phys. Teach. 24, 472 (1986).

[111] I. Galili, Students' conceptual change in geometrical optics, Int. J. Sci. Educ. 18, 847 (1996).

[112] I. Galili, S. Bendall, and F. Goldberg, The effects of prior knowledge and instruction on understanding image formation, J. Res. Sci. Teach. 30, 271 (1993).

[113] A. Field, Discovering Statistics Using IBM SPSS Statistics (Sage, Thousand Oaks, CA, 2013).

[114] G. J. Smith, M. M. Schmidt, P. J. Edelen-Smith, and B. G. Cook, Pasteur's quadrant as the bridge linking rigor with relevance, Exceptional Children 79, 147 (2013). 